\title{
WestVirginiaUniversity
}

THE RESEARCH REPOSITORY @ WVU

Graduate Theses, Dissertations, and Problem Reports

2021

\section{Enacting Sustainability in Footwear Product Development}

\author{
Mary Samantha Hale \\ West Virginia University, mshale@mix.wvu.edu
}

Follow this and additional works at: https://researchrepository.wvu.edu/etd

Part of the Environmental Studies Commons, and the Public Affairs, Public Policy and Public

Administration Commons

\section{Recommended Citation}

Hale, Mary Samantha, "Enacting Sustainability in Footwear Product Development" (2021). Graduate Theses, Dissertations, and Problem Reports. 8013.

https://researchrepository.wvu.edu/etd/8013

This Thesis is protected by copyright and/or related rights. It has been brought to you by the The Research Repository @ WVU with permission from the rights-holder(s). You are free to use this Thesis in any way that is permitted by the copyright and related rights legislation that applies to your use. For other uses you must obtain permission from the rights-holder(s) directly, unless additional rights are indicated by a Creative Commons license in the record and/ or on the work itself. This Thesis has been accepted for inclusion in WVU Graduate Theses, Dissertations, and Problem Reports collection by an authorized administrator of The Research Repository @ WVU. For more information, please contact researchrepository@mail.wvu.edu. 
Enacting Sustainability in Footwear Product Development

Mary Samantha Hale

Thesis submitted to the

Davis College of Agriculture, Natural Resources and Design

At West Virginia University

in partial fulfillment of the requirements for the degree of

Master of Science

in

Fashion Design and Merchandising

Kathryn Jones, Ph.D., Chair

Debanjan Das, Ph.D.

Craig Nelson, MID.

School of Design and Community Development

Morgantown, West Virginia

2021

Keywords: Sustainability, Footwear, Product Development (C) 2021 Mary Samantha Hale 


\section{Abstract \\ Enacting Sustainability in Footwear Product Development \\ Mary Samantha Hale}

The apparel and footwear industry's negative environmental impacts have companies facing scrutiny as consumer environmental consciousness increases (Brewer, 2019). Apparel and footwear companies are scrambling to develop sustainable initiatives with more consumers demanding they be held accountable for their actions. The industry has focused on recycling, raw materials sourcing, and reducing production waste during product development for more sustainable outcomes. This qualitative case study explores how sustainability as an abstract corporate initiative affects footwear companies and product development processes. The best way to explore how companies engage and execute sustainable practices in their product development process is by examining it in context. With that in mind, this study was set into the product development department at footwear companies, engaging directly with members of footwear product development teams, both full-time employees and freelancers. The research seeks to understand how footwear product developers conceive their role in contributing to the corporate structure's sustainability initiatives. I conducted a phenomenological case study to better understand the product developer's sustainability experiences in footwear design. Interpretivism, accompanied by a phenomenological approach, centralized the informant's lived experience and the meaning they ascribe to their practices (Wilson, 2015.) Interviews with four purposely selected informants provided insight into their positions and perspectives. The interviews consisted of a series of semi-structured, open-ended questions. Another series of questions were developed informed by the SVAT (Sustainable Value Analysis Tool). This tool provided a coding structure to better understand how the practices of these particular informants would be framed through an established, industry lens. The findings highlighted the relationship between sustainable goals set in place by companies' corporate structures and the enacted practices of employees in product development roles. Areas in which the informants expressed influence was in circular design initiatives, utilization of recycled materials, information sharing, and logistical tracking of manufacturing processes. These initiatives all aligned with stated goals of the companies. Pursuing recycled materials in footwear products resulted in challenges as the product development teams encountered quality and durability issues specifically with recycled plastics and rubbers. These challenges became a barrier in reaching goals at both Company $\mathrm{M}$ and Company S. Product development teams of both companies recognized ways in which they could strategically incorporate the recycled materials into footwear products resulting in innovation and successful initiatives. Interviewees expressed that the newness of sustainability as a focus in the footwear industry is contributing to the current barriers and challenges footwear developers are facing. Interviewees shared their hopes that as the focus matures, innovations will lead to further growth in sustainability opportunities. The SVAT (Sustainable Value Analysis Tool) further elucidated findings by breaking down the beginning, middle and end of a product's life. By aligning the interview questions with this method of SVAT the study found that most companies are focusing their efforts on the beginning-of-life (BOL) stage Specifically, they are focusing on design and material make up of footwear products. 


\section{Acknowledgements}

I wish to thank all the people whose assistance contributed to the achievement of this project. I would first like to thank my thesis advisor, Dr. Kathryn Jones for taking on this role and guiding me through the process. Dr. Jones helped me build confidence in higher academia by encouraging my voice and position as researcher. I am grateful for the structure and support she provided throughout this journey.

I would like to thank Professor Beth Shorrock for providing a learning environment in undergraduate classes that stimulated my interest in sustainability in fashion. Professor Shorrock impacted my life in away many professors hope to and provided me with opportunities to further my focus on sustainable that led me to pursue a graduate degree.

I would also like to acknowledge Dr. Debanjan Das and Professor Craig Nelson for serving on my committee. They created a great support team for me and assisted me throughout the project. Both helped mold my graduate experience by providing a comfortable learning environment. I thank Dr. Das for assisting my first research project in the graduate program that ultimately led to the topic of my thesis. I thank Professor Craig for motivating my design passions by enlightening ways to simultaneously combine creativity and research in my future.

Lastly, I would like to acknowledge Professor Peter Butler as the Director of Design and Community Development for offering me a graduate research assistantship. The opportunity allowed me to successfully pursue a master's degree and enhance my knowledge in areas of research and sustainability. 


\section{Table of Contents}

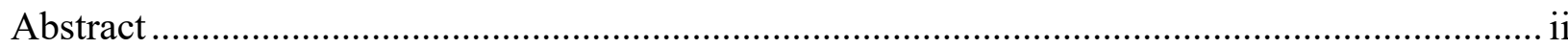

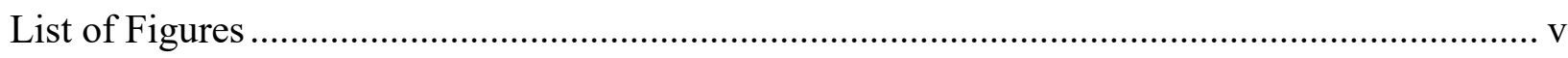

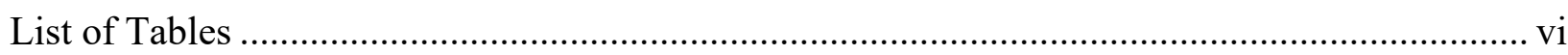

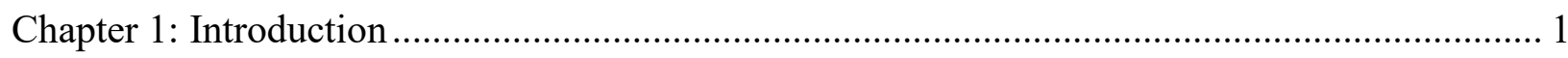

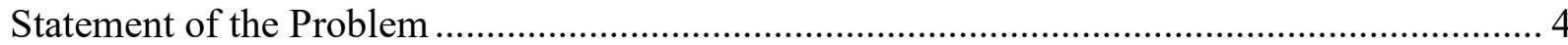

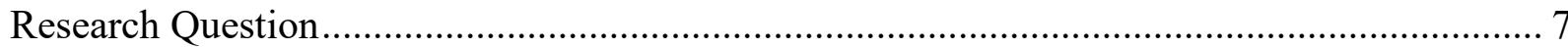

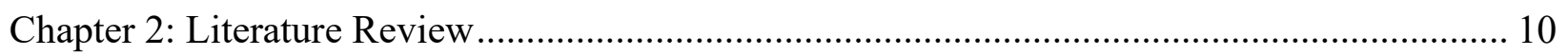

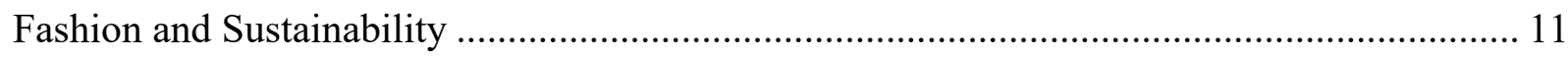

Sustainability and Transparency in Global Marketplace .................................................. 14

Sustainability in Product Development........................................................................ 18

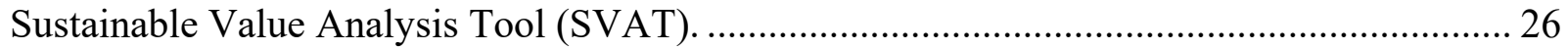

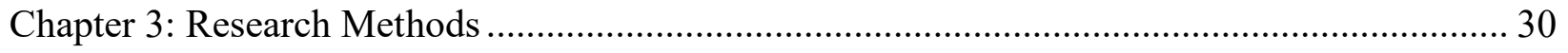

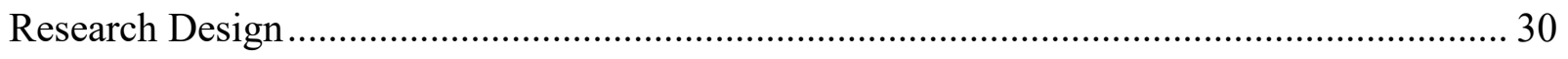

Phenomenological Research Paradigm ....................................................................... 31

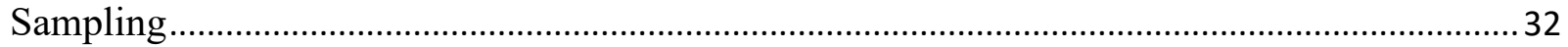

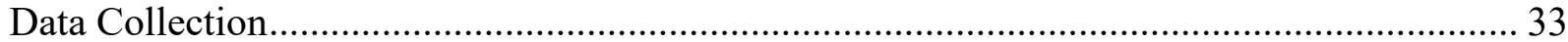

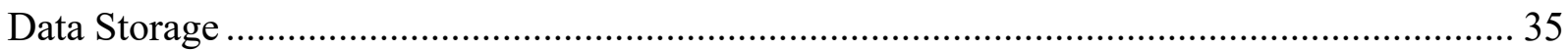

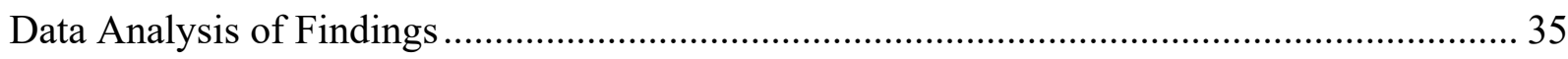

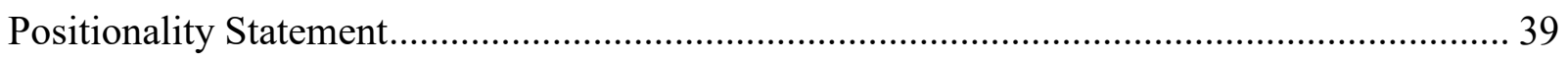

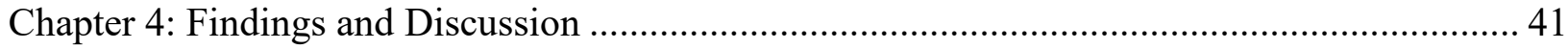

The Product Developers and their Context …...................................................................... 41

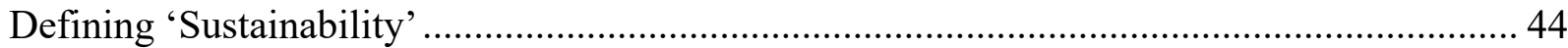

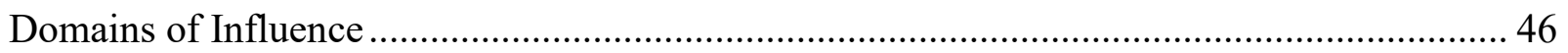

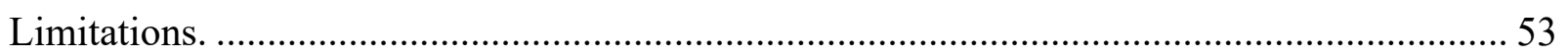

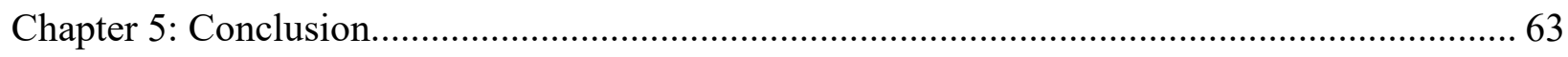

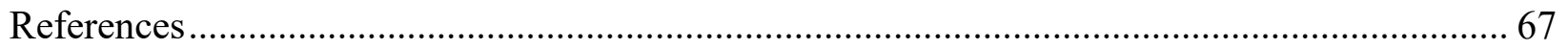

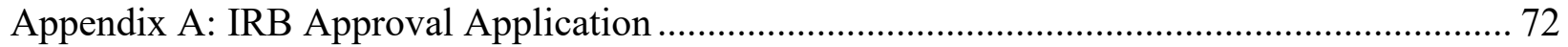

Appendix B: Participant Recruitment Letter ................................................................ 74 


\section{List of Figures}

Figure 1. Sustainable Value Analysis Tool..................................Error! Bookmark not defined.

Figure 2. Value Propositions....................................................Error! Bookmark not defined. 


\section{List of Tables}

Table 1: Summary of Participants from Footwear Product Development................................ 42

Table 2: Demographic Based Interview Questions ......................Error! Bookmark not defined.

Table 3: Sustainability Based Interview Questions .......................Error! Bookmark not defined.

Table 4: SVAT Based Interview Questions.................................Error! Bookmark not defined.

Table 5: Production Based Interview Questions...........................Error! Bookmark not defined. 


\section{Chapter 1: Introduction}

In the last century, industrialized society has shifted how it procures and discards apparel products. This includes moving from domestic manufacturing and most consumption happening at the local level to global manufacturing and omnichannel consumption models. The emergence of the first factories in 1810 eventually led to clothing's mass production (Ertekin and Atik, 2014.) Ready-to-wear (RTW) - clothing fully ready for consumption at the point of purchase became accessible for women around 1910 (Ertekin and Atik, 2014). As mass-production manufacturing advanced, RTW clothing expanded. Manufacturers' pursuit of replicating highquality materials and dyes affordably grew with RTW expansion (Lueg et al., 2013). To achieve this replication, manufacturers began developing synthetic fibers and dyes. For example, nylon was invented to replicate silk in the late 1930s (Wolfe, 2008). Rayon and acetate were other artificial fibers that helped drive down the cost of RTW clothing. From that, manufacturers sought to fill the markets with synthetic materials.

Then, globalization provided manufacturers with more opportunities to source cheaper labor and materials (Lueg et al., 2013). The newfound resources allowed fashion production to become quicker and cheaper. Countries working toward industrial development saw this as an opportunity to join the growing market of clothing production. As globalization grew, so did access to fashion imagery. Clothing styles and trends once took time to trickle out to the suburbs and rural areas. By the end of the $20^{\text {th }}$ century, however, consumers could view the latest styles immediately through the internet. These factors challenged how people viewed and consumed clothing, resulting in fast fashion (Ertekin and Atik, 2014). In a fast fashion context, consumers purchase more items throughout the year than the previous two-season lifecycle (Lueg et al., 
2013). With this fast-paced production came negative ethical and environmental repercussions within fashion production (Lueg et al., 2013). The public became aware of the malpractices of apparel companies and demanded accountability. As product development and production were offshored, companies became disconnected from the manufacturing process. In response to rising consumer concerns, companies established corporate social responsibility (CSR) initiatives and built models to implement sustainability into product development (Lueg et al., 2013). While CSR's models respond to the demand for company transparency, they do not provide an adequate solution for the apparel industry's negative footprint. CSRs fall short of an adequate solution for several reasons, one being they do not apply to the entire business model. Companies' CSR's provide unrealistic compliances for selling firms to adhere to codes, produce for deadlines, and improve their working environments (Park and Dickson, 2008). There is not a single standard CSR for apparel and footwear companies. Instead, each company has its own CSR's and regulations they expect from manufacturers it leads to confusion for sellers. Thus, each apparel and footwear companies must find ways to manage and maintain their corporate codes while manufacturing offshore.

Access to fashion imagery and internet-based social media also provides a platform for voices to raise concern to a large audience on fast fashion's ethical dangers, calling out companies for their actions (Chu and Kim, 2011). Now consumers are demanding transparency and change within companies' product development (Lueg et al., 2013). Consumer demands for sustainability go against the recent growth of fast fashion and modes of production. As apparel companies yearn to remain competitive in the ever-changing market, they must listen to their consumer's demands (Lueg et al., 2013). Their consumers' rising environmental consciousness 
means apparel companies are pressured to implement sustainability into their existing product development models.

Sustainability continues to be a rising focus within the apparel industry. After years of environmental devastation and unethical production systems, the apparel industry continues to face scrutiny (Park and Dickson, 2008). In response, apparel companies have adopted sustainable approaches to immediately answer the demands of consumers' environmental concerns and the growing environmental regulations. As we delve deeper into the complex apparel industry's issues, the need for social and economic changes to complement environmental efforts becomes clearer (Bocken et al., 2013). Apparel companies implement sustainable approaches that fit into their current business models that focus on generating economic profit through sales to their target market (Bocken et al., 2013). Studies show that sustainability can be profitable when implemented into the holistic system not just focusing on the consumer end as many have done (Evans et al., 2017).

Apparel and footwear companies are met with the challenge of reconstructing their current business models to achieve environmental, economic, and social sustainability. This research explores how companies are engaging in sustainability within product development. Specifically, this research focuses on sustainability engagement amongst those engaged in footwear product development. These workers' perceptions offer insight into direct experiences of product developers as they contribute to the overall success of corporate sustainability initiatives. From these firsthand experiences we can start to identify problem areas and successful initiatives as companies implement sustainability. The findings contribute to the larger 
conversation of navigating sustainable initiatives in apparel and footwear companies, specifically within product development narratives.

\section{Statement of the Problem}

Companies need to engage sustainable production models to manage further socioenvironmental devastations and remain competitive in the vast market (Chan et al., 2020). Implementing system thinking to understand the current model's micro and macro levels is crucial to change (Evans et al., 2017). CSRs provide companies a competitive advantage and transparent solution to the arising problem with success in controlling labor issues in offshore manufacturing (Chan et al., 2020). However, CSRs do not fix the problem of negative environmental impact but contribute to uncovering underlying issues (Evans et al., 2017).

Implementing sustainability into existing product development models may enhance the life cycle through innovation and technical advancements (Ertekin and Atik, 2014). The manufacturing of footwear products focuses on large quantity, centralized manufacturing, and the use of materials. Research shows that the relationship between designers, buyers, and sellers contributes to sustainable management effectiveness (Park and Dickson, 2008). Bridging the gap between these entities results in more effective implementation of the sustainable initiative. However, this is not always possible for low-cost business models (i.e. fast fashion companies) (Lueg et al., 2013). Further, apparel and footwear companies with high-volume orders tend to gain a better relationship with manufacturers.

In contrast, apparel and footwear companies with smaller orders or lower price demands may not create relationships with manufacturers as well. Because manufacturer's goal is to profit, they seek relationships with companies that provide larger order volumes. The absence of 
a relationship results in the lack of ability to maintain and manage CSR's and sustainable corporate initiatives (Park and Dickson, 2008). Bocken et al. (2013) argue that initiating sustainable change throughout the entire business model is the most effective solution. Resources such as a sustainable value analysis tool (SVAT) have helped companies integrate sustainability (Yang et al., 2014). This tool allows for the analysis of current business models and helps identify where there is room for sustainable value, providing insight into how changes to the corporation's business model could increase value (Evans et al., 2017).

Apparel companies need to change their business models to effectively implement sustainability into product development and gain value (Evans et al., 2017). Product-service systems have been introduced as a strategy that allows companies to enhance the product life cycle and continue to interact with consumers, gain loyalty, and prolong the product's monetary value (Yang et al., 2014). The product-service system provides stakeholders social and environmental benefits. Existing research on how this system and sustainable value analysis tools work within apparel and accessory companies is somewhat limited. Therefore, this paper will apply sustainable value analysis while exploring a footwear company's product development process. The SVAT can be applied to both companies with and without sustainable initiatives. The tool is applied to a single product's entire life cycle to analyze a potential sustainable value that is currently being missed and identifies the current captured sustainable value (Evans et al; 2017). This research looks at companies that may have corporate sustainable initiatives or goals to identify how they affect product development. 


\section{Significance of the Problem}

The apparel industry is under scrutiny to change its current production models (Ertekin and Atik, 2014). The consumer-driven market is highly segmented, and each company must identify the strategies most likely to attract an audience. While some companies provide transparency and slow production to provide sustainable alternatives in the market, other companies continue to saturate the market with quick lead times and low-cost garments. The athletic footwear industry has been a target for criticism from journalists and activists ( $\mathrm{Yu}$, 2007). Nike was one of the first targets of child labor issues when images and accounts were made public. In 1996 a magazine publication printed a child labor article that included a photo of a young boy working on a Nike soccer ball (Locke, 2002). The publication created a lot of criticism from consumers that was already building from previously released images and articles incriminating the company of child labor. This criticism results in the athletic footwear sector leading the industry in CSRs and sustainable innovation (Yu, 2007). There are numerous ways designers and companies initiate sustainability in products, such as raw materials and processing (Jacques et al., 2010).

Before consumer awareness that fast fashion is detrimental to the quality of life rose to a critical level, companies based their business models on speed and cost-effectiveness (Ertekin and Atik, 2014). Now companies are faced with making changes to these current structures. Companies' next step toward sustainable growth is restructuring the whole business model (Evans et al., 2017). This research aims to understand the effectiveness of implementing sustainability at a corporate level and the experience of individual product developers when 
implementing those strategies. Past studies have suggested that CSR and corporate initiatives may not be effective in fulfilling sustainable initiatives (Park and Dickson, 2008).

\section{Research Question}

This research's overall guiding question is: How do footwear companies engage and execute sustainable practices in their product development process? Additionally, I seek to understand how footwear product developers conceive their role in contributing to the corporate structure's sustainability initiatives.

\section{Theoretical Framework}

Research suggests that system thinking provides companies an opportunity to problem solve and create solutions that influence multiple found issues (Evans et al., 2017). For this to happen, companies must think across the entire product lifecycle. When evaluating and analyzing the entire product lifecycle, potential sustainable values can be determined (Evans et al., 2017). These concepts are based on sustainable value tools (SVATs) and methods. When applied to current business models, these tools and methods can access current value and the opportunity for sustainable value creation (Yang et al., 2014).

The theory of sustainable value creation is viewed as an approach to create maximum value out of the resources used and the product's lifecycle (Yang et al., 2014). Evans et al (2017) argues that missed value or uncaptured value is where value opportunity lies. Value refers to broad social, environmental, and economic benefits. This value term includes laborers' welfare, economic profit generated beyond sales to consumers, offset of emissions, and other factors found when implementing sustainability. This value is analyzed by looking at the entire life cycle. Product service systems (PSS) is a strategy implemented by companies to increase 
products' value and proposes areas to implement sustainability (Yang et al, 2014). The creation of the following concepts guides the successful initiation of sustainability in PSS development. Concepts for sustainable value analysis tool for value creation begin with life cycle thinking where products are thought through all stages in ways the products lessen environmental impact and use of materials (Yang et al, 2014). These stages include materials selections, consumer use, and the post-consumer opportunities of a product. Sustainable value as a concept includes potential stakeholder and environmental benefits (Yang et al, 2014). The third concept is multiple forms of value. This concept analyses the current negative aspects by looking at value destroyed (VD) and value missed (VM) ((Yang et al, 2014).

These steps encourage business leaders to see opportunity in their uncaptured value through the lens of sustainability. Though according to Evans (2017), this step-by-step process does not provide the identified opportunities with a plan of realization and solution, these SVAT concepts merely assist the strategy of PSS. The literature review will provide a detailed analysis of the SVAT's relevance and applicability generally and to the footwear industry specifically.

\section{Summary}

Today, many companies use sustainability as a marketing tool (Yu, 2007). Sustainability holds more opportunity than just driving consumers toward a product, however. For a long time, fast and cheap demands drove manufacturing (Ertekin and Atik, 2014). Consumers' interest in sustainability is piquing. The environmental impact of clothing and accessories is no longer a secret, and companies are held accountable for their actions. Utilizing the SVAT tool can provide companies with solutions and multiple sustainable benefits (Evans et al., 2017). These benefits can present as appealing to companies regarding economic, social, and environmental 
advantages (Yang et al., 2014). The utilization of this tool means companies can analyze the effects of sustainable initiatives before they implement them.

Although SVAT has been a successful way to analyze potential benefits, apparel and footwear companies are faced with the barrier of the global market. SVAT will allow apparel and footwear companies to see potential benefits in the product development process, but these benefits may not be easily obtainable. This study explores the opportunities to close the gap between corporate and individual employee objectives in the footwear industry to achieve better sustainability effects. To do this the study explores the role of product developers. Product developers lived experiences provide insight to their engagement with sustainability initiatives. While sustainable initiatives are recognized this study aims to understand how those initiatives are carried out amongst the product developers. 


\section{Chapter 2: Literature Review}

\section{Introduction}

The purpose of this literature review is to explore the role of sustainability within the apparel industry. The literature review will set the context and background needed to ask the study's research question: how do footwear companies engage and execute sustainable practices in their product development process? Additionally, the literature review will provide the groundwork needed as I seek to understand how footwear product developers conceive their role in contributing to the corporate structure's sustainability initiatives.

The first research area focuses on the emergence of fast fashion and the issues that developed around it. The exploration of the apparel industries' transition into the current, unsustainable mode of production provides a general understanding of the issues companies and manufacturers face. This section explains the negative effects from the industry's shift into fast fashion. Sustainability is presented in this section as a response to the negative impacts of fast fashion. The second section moves into the apparel industry's role in the global market. The exploration of globalization reflects the importance of transparency as a barrier to sustainability. This section highlights sustainable initiatives that companies try to incorporate to achieve sustainability in a global market. The third area of research focuses on sustainability's roles in different areas of apparel manufacturing. This focus aims to understand how companies have pursued sustainability and the effects of those initiatives.

It is important to understand some of the models and concepts companies present to initiate sustainability. This literature review does not explore all types of sustainable expansion in the apparel industry. The aim is to understand some barriers and success that come from 
sustainability within apparel production. Finally, the literature review focuses on footwear companies to further understand the specificity of the market. The exploration of footwear companies allows for the exploration of a specific product. This focus area gives a narrower approach to the research study.

\section{Fashion and Sustainability}

Previously, the apparel and footwear market were affected by two significant events: restructuring social hierarchy by democracy and the rise of factories' resulting in mass production capabilities (Ertekin and Atik, 2014). Factories changed how people produced and consumed fashion (Bhardwaj and Fairhurst, 2010). While limits still existed on what the commonwealth has access to, social hierarchy was being tested by the end of the $18^{\text {th }}$ century (Ertekin and Atik, 2014). New factory production models allowed for mass production of RTW garments granting access to the commonwealth. This production enhanced growth in the participation of clothing purchases amongst all social classes. What was once a scarcity was made accessible due to mass production by the late 1800s (Ertekin and Atik, 2014).

The apparel industry was once driven by a two-season model and garments' mass production (Bhardwaj and Fairhurst, 2010). Mass production allowed for the marketing of apparel to the masses and offered a strategic supply. Consumer demand also emerged as a new driving force, urging quicker production and mirroring trends as they appeared in high fashion (Lueg et al., 2013). Apparel production began moving offshore to low-cost manufacturing in the late 1980s and early 1990s, which gave companies a cost advantage (Bhardwaj and Fairhurst, 2010). With this change in manufacturing models', companies began to see buyer-driven product advantage in the growing market. That is, companies sought to exploit buyers' price demands as 
leverage with manufacturers to create products quickly (Bhardwaj and Fairhurst, 2010). Buyerdriven products gave companies the advantage of separating themselves from each other and creating products to fill the market gap. The competitive corporate restructuring changed fashion production and consumption. Another aspect that led to companies' advantage for buyer-driven products was consumers' growing access to fashion imagery. Consumers' access to fashion imagery that was once only available to those in the industry led to a disruption in fashion's trickle-down effect (Ertekin and Atik, 2014). Companies quickly noticed the market gap and acted to provide consumers with replications of the fashion imagery as quickly as possible. These two shifts in production models were the integral to the rise of 'fast fashion' (Bhardwaj and Fairhurst, 2010).

The fast fashion industry is driven by speed, cost advantage, and accessibility (Fletcher, 2014). Companies focus on quick response strategies to achieve this speed and cost-effectiveness (Bhardwaj and Fairhurst, 2010). These strategies provoke production models that exploit labor and resources (Kumar et al., 2017). Companies demand a shortened lead time from their suppliers to fulfill orders. Immediately negative results appear as working conditions and labor ethics are tested. The effects of fast fashion production in apparel and footwear industries include negative environmental impact, depletion of resources, waste, and exploitation of consumers and laborers (McRobbie, 1997). Since the emergence of fast fashion, the rate of clothing purchased annually grew $60 \%$ from 2000 to 2015 (Chan et al., 2020). This growth resulted in the rise of carbon dioxide emissions. Consumers are increasingly aware of the fast fashion model's negative impacts and, as a result, increasingly interested in more sustainable options (Eretkin and Atik, 2014). 
Sustainability in fashion, for this context is defined as "the movement and process of creating clothes, shoes, accessories and other textiles through sustainable practice that take into account environmental, social and economic implications" (Gongini, 2017, para. 3). This definition guides the apparel industry to new models, methods, strategies, and techniques to manage resources and ecological impact. The diversity and complexity of implementing sustainability into the globalized product development models come with barriers for companies and even leading scholars to argue that no product can be "regarded as perfectly sustainable" (Moon et al., 2013, p. 393).

The rise in consumer and industry awareness suggests a slow fashion movement is now possible (Brewer, 2019). Slow fashion presents a new model of how we procure, consume, and dispose of fashion. The new model spreads awareness of the impacts on workers, communities, and ecosystems for the designers, buyers, retailers, and consumers (Fletcher, 2014). Concerns about the apparel and footwear industry's negative global impact are rising. These concerns are resulting in an increase of discussion amongst firms and design educators. Implementing new production models driven toward slow fashion concepts is a part of the discussion. Though, implementing sustainability faces many barriers. One such barrier is the lack of transparency in the globalized market, which hinders the development of a sustainable fashion system (Ertekin and Atik, 2014). Transparency in the global market includes the traceability of the manufacturing process. To achieve sustainability, Kumar suggests that being able to track, record, and share information of the manufacturing process between buyers and sellers is of key importance (et al., 2017). Transparency allows companies to manage and maintain where resources are being used, where waste is produced, and where products cause environmental impact. For consumers, 
transparency in the supply chain offers the ability to hold manufacturers accountable and assess their commitments to promises made. Consumers have expressed willingness to pay more for more transparent products (Kumar et al., 2017).

\section{Sustainability and Transparency in Global Marketplace}

To navigate fast-paced production, firms began to outsource to the global market around 1980 to 1990s (Bhardwaj and Fairhurst, 2010). The global market of apparel production consists of raw materials, dying, finishing processes, cut-and-sew, transportation and laborers. All these aspects create an offshore supply chain with little traceability (Kumar et al., 2017). Traceability is used as a method of transparency in the global market. Transparency is defined by Fashion Revolution (2020) as "the public disclosure of credible, comprehensive and comparable data and information about fashion's supply chains, business practices and the impacts of these practices on workers, communities and the environment" (n.p.). As the negative impacts of off-shore production continue to concern consumers, transparency in production models becomes more relevant. Transparency is an appealing factor for environmentally conscious consumers (Kumar et al., 2017). Some companies can work closely with their off-shore producers to obtain transparency and traceability in their supply chains. This does not mean that the company is sustainable. It means that the company can trace the environmental impacts of their products, making transparency crucial for sustainable development.

In search of ways to combat transparency barriers in the globalized market, companies are presenting innovative models and suggested strategies to mobilize sustainability and slow fashion models. Turner (2019) presents Re- Distributed Manufacturing (RDM) as implementation or alternative to current business models. The model of RDM aims to "help 
change the organization of manufacturing in terms of location and scale to reduce supply chain costs, improve sustainability and provide customizable products" (Turner et al., 2019, p.1). This model presents economic and environmental benefits, which businesses and consumers look at when evaluating sustainability. To some, the idea of sustainability implies the concept of limiting or regressing economic growth (Dolan and Peasgod, 2006). RDM uses innovative technology to ensure more efficient use of resources, combatting overproduction and waste issues resulting in possible monetary benefits (Prendeville et al., 2016). Localization of manufacturing is an enormous transformation that RDM presents as an alternative to full-scale globalization and contributes to the circular economy's idea. A circular economy (CE) requires the design process to consider the product's whole lifecycle, including end life. This research suggests that companies can apply this proposed model and reap its benefits in their current production methods.

Globalization and centralization of apparel and footwear manufacturing contribute to exploiting labor and resources (Yu, 2007). At the same time, globalization contributes positively to economic and trade growth. This growth impacts the way industries utilize and procure resources increasing competitiveness in the market. Cheap labor and manufacturing materials have been a competitive advantage driving countries to maximize their profits (Penayotou, 2000). However, the emphasis on global economic benefit has resulted in a deterioration of global environmental standards. Further, there is a lack of consistency in international sourcing regulations (Jacques et al., 2010). Manufacturing companies are blamed for the repercussions of using chemicals and hazardous materials (Jacques et al., 2010). These handoff responsibilities have previously allowed companies to separate themselves from the negative environmental 
impacts manufacturing their products causes, known as 'externalities.' Further, globalization has created a power imbalance in the buyer and seller relationship (Kumar et al., 2017). This power imbalance has created barriers when sellers try to enforce their newly developed sustainability models. Power imbalance is caused by corporations' ability to demand cheap labor and materials pricing by threatening to abandon the relationship.

Corporate Social Responsibility (CSR), Corporate Sustainability (CS), codes of conduct, monitoring systems, and Non-Governmental Organizations have all been employed as methods by companies for controlling quality, ethics, and ecological impact in their manufacturers ( $\mathrm{Yu}$, 2007). Companies use CSR to present an image of their social and environmental initiatives and the standards they withhold in the companies' endeavors (Lueg et al., 2013). CSR affects how a company builds relationships with consumers and manufacturers (Chan et al., 2020). CS is a strategy coinciding with CSR's that companies use to address their focus on the environmental impact of their products. Companies use techniques like codes of conduct and monitoring systems to control their CSR's and CS compliance (Yu, 2007).

However, scholars such as Park and Dickson (2008) have shown that these methods are ineffective in ensuring compliance with companies' sustainable requirements in manufacturing their products. The distance between buyers and sellers results in a lack of communication and confusion between the two parties. Sellers find themselves confused by the varying CSR and CS codes upheld by each firm resulting in them being unable to comply (Park and Dickson, 2008). Corporations push large orders expecting manufacturers have the viable resources to fulfill orders and remain in compliance with their codes and labor regulations. Since enforcing CSR's from afar is ineffective for buyer's, Park and Dickson (2008) suggested building relationships 
with manufacturers as an alternative strategy to monitor codes' compliance. In this relationship, buyers and sellers work together to implement a company's initiatives with incentives for future engagements between the two parties. The partnership allows manufacturers and buyers to further understand each other's expectations.

One strategy companies can employ to hold manufacturers accountable is to implement a traceability model that monitors data throughout the supply chain (Marconi et al., 2017; Torres et al., 2010). Marconi presents a traceability model that monitors data amongst the supply chain in chemicals used, material inputs, electricity usage, and monitoring factory environment. Implementing traceability models provide a baseline comparison of products and suppliers for consumers (Marconi et al., 2017). Collecting data within global supply chains and monitoring the production inputs and outputs to share information and outcomes with others is essential to mobilizing sustainability in the worldwide market (Kumar et al., 2017). The data can provide companies and other manufacturers with details on how current production models compare to when sustainable models are implemented and positively affected. Traceability models as a sustainability initiative informs this research by providing data on the effects of sustainability in product development.

Building on this previous research that detailed a complex global market, enumerated the challenges and opportunities for sustainable initiatives, and recommended developing close relationships amongst supply chain members, this research questions how existing shoe companies operate compared to these models. The study will analyze how the relationship with manufacturers has affect their sustainable efforts by speaking directly with those working within the supply chain. 


\section{Sustainability in Product Development}

The process of producing a footwear product encompasses many stages. These stages include design, material selection, sourcing, and cost (Curwen et al., 2013). While design is a stage in product development, designer and product developers hold different roles. A designer creates a concept that incorporates the motive of the product with consumer's needs (Curwen et al., 2013). Additionally, designers can implement sustainable initiatives into the footwear product by designing the footwear product around minimal material usage and usability at end of life (EOL). Product developers' roles include selection and sourcing of materials and managing the cost and pricing of the overall product. Product developers are also tasked with communicating with manufacturers and vendors ensure their footwear products are correctly manufactured (Jacques et al., 2010). Jacques (2010) suggests that companies with sustainability initiatives in their business model place importance on their relationships with manufacturers and supply chains. Thus, a product developer is poised to play a key role in the implementation and success of corporate sustainability initiatives.

At the beginning stage of product development, sustainable initiatives like zero waste and CE may be integrated into the design process. CE aims to reduce disposal and waste of resources by designing the materials that can be recycled and regenerated into new utilizations (Turner et al., 2019). Implementing CE models can result in economic, social, and environmental benefits. Zero waste design -where no scrap is left behind- essentially produces products that utilize all materials procured in some way (Murray, 2002). Both zero waist and CE can be implemented at the design stage of product development. Both result in reduced development in the 
manufacturing process. Although, CE faces the challenge of consumers following through with the EOL plan for reutilization of the product (Curwen et al., 2013).

Socially responsible buying and sourcing is an integral part of implementing sustainability in product development (Park, 2005). Park (2005) suggests that producers need to integrate business ethics into buying and sourcing to create a socially responsible strategy that allows for measuring ethics alongside the profit gain. Footwear and apparel industries measure their environmental impact by focusing on processing and using raw materials (Jacques et al., 2010). While measuring ecological impacts, findings suggest utilizing chemicals and nonrecyclable synthetic materials in production processes create a series of health and environmental concerns (Jacques et al., 2010). Globalization has placed additional responsibility on buyers to source materials (Kumar et al., 2017). However, this change in responsibility has also resulted in companies shifting blame for negative environmental and social impacts onto global suppliers.

Supply chain management plays a pivotal role in initiating the effective use of resources and building relationships with suppliers. In strategic sourcing, selling firms can diversify themselves successfully by utilizing resources in their environment according to resource-based views of firms referenced from Dickson (Barney, 1991). Kate Fletcher presents localization as a sustainable way to procure resources (Fletcher, 2014). However, this may not be a feasible course of action for large apparel and footwear companies. Local strategies could add competitive value to smaller companies and provide a more holistic approach to sustainability. Strategic sourcing and supply chain management is crucial to carrying out design developments and product life cycle analysis to ensure that proper resources and materials are selected. I argue that implementing localization as a sustainable method in sourcing provides both small and large 
companies an opportunity. This study looks at how shoe companies of different sizes have been affected by sourcing sustainably.

Sustainability is increasingly viewed as a competitive advantage in the apparel and footwear market. While competitive advantage emanates from low-cost strategies in fast fashion, Chrisman (et al., 1998) suggests that a low-cost process is only competitive when the product's low cost is what differentiates it in the market. Therefore, the low-cost market's oversaturation suggests that sellers can seek this as an opportunity to breach competitiveness in the sustainable market. According to Park and Dickson's 2008 study, firms look for manufacturing efficiency and product supply to increase their competitiveness. Firms outsourcing from different suppliers are always faced with assuring their company's needs in terms of efficiency and product supply and are unable to shift focus to other markets. Park and Dickson (2008) illustrated how strong partnerships that produce fair labor standards can also prove to be their own form of competitive advantage.

As consumers demand accountability and slow fashion approaches offer firms competitive advantage, small footwear companies are growing in the market. Additionally, NonGovernmental Organizations (NGOs) that provide guidelines, award certifications, and help implement monitoring systems are also proliferating. For example, the Sustainable Apparel Coalition (SAC), launched in 2010, provides both large and small apparel and footwear companies with a tool to assess the impact of their production decisions. This coalition provides an umbrella of information for members. Currently, "SAC members are estimated to be responsible for more than one-third of apparel and footwear produced globally" (Radhakrishnan, 2014). 
The Fair Labor Association (FLA) is another group that provides guidance for the apparel and footwear industry by auditing factories for their members. Thus, the FLA helps accredit companies' sustainable initiatives (Locke, 2002). For example, the audits have helped Nike eliminate petroleum-based chemicals in production (Locke, 2002). These third-party groups provide guiding information and resources for companies in their sustainable initiatives and share innovation appealing to companies. They also provide a regulatory system for determining a company's competence in sustainability. With the rise of sustainability as a marketing trend, these organizations help certify claims made by companies, increasing the company's legitimacy in the sustainable fashion marketplace.

\section{Footwear companies as case studies in sustainable PD}

Only ten footwear companies, including Nike, Reebok, and Adidas, make up $70 \%$ of the global athletic footwear market (Locke, 2002). The footwear industry currently produces around 20 billion pairs of shoes yearly, with each pair of footwear on average producing 30 pounds of carbon dioxide when including materials, manufacturing, and transportation (Sameer, 2020). Common problematic materials used in footwear include polyvinyl chloride (PVC), synthetic rubber, polyester, polyurethane, and leather (Filho et al., 2019). The increasing use of plastics in footwear is creating an alarming end-of-life pollution problem once consumers discard their used products (Filho et al., 2019). One proposed solution is for footwear manufacturers to develop 'take-back' programs to recycle the plastics at the end of the shoe's life, potentially lessening environmental pollution.

There have been numerous reports of footwear factories releasing dangerous chemicals that cause several side effects such as heart disease and respiratory illness (Locke, 2002). While 
manufacturing plants have made efforts to control their environmental pollution and chemical releases in recent years, the side effects of factory pollution are still being studied. Manufacturing utilizes " $80 \%$ of the resources used by the supply chain through consumption of raw materials, energy, and water" (Subic et al., 2012). From this, we can see that the manufacturing process contributes to a large portion of a product's negative environmental impact. Subic et al. (2012) noted the importance of focusing research on sports apparel and footwear supply chains. Because the global market is so complex, manufacturing companies may not provide the accurate information needed for analyzing a product's life cycle. Thus, more studies are needed to better articulate the opportunities and challenges facing footwear companies as they address environmental and social concerns.

The rise of environmental awareness has led consumers to focus criticism on the apparel and footwear industry, demanding action, and accountability. Apparel and footwear companies respond by pursuing sustainability from many avenues according to their placement in the market. Many are creatively leading by innovating sustainable solutions in the product life cycle, design, and manufacturing. Nike has been at the forefront of innovating material for footwear. For example, their ColourDry technology allows for waterless fabric dying and has saved over 20 million liters of water, which would have otherwise become a wasted resource (Moorhouse and Moorehouse, 2017). Water, a scarce resource, is overused and polluted by apparel, and footwear companies during production, becoming a top priority in initiatives that rethink usage and waste (Jacques et al., 2010). Nike's approach to waste also led to the development of Nike Grind. Nike Grind processes and regenerates its products to reduce manufacturing waste (Moorhouse and Moorehouse, 2017). The grind incorporated rubber waste from the production 
process by grinding the material and reforming it into new usable material. The material is then used in sneakers and other footwear products. Though, utilizing waste materials in this recycling process can degrade the quality and overall durability, also known as 'downcycling.' Another Nike innovation, Flyknit technology, has contributed to lowering almost 3.5 million pounds of waste (Nike, 2016). Flyknit material is made up of recycled materials that have been broken down and recycled into a highly technical polyester fabric specifically for light weight sneakers.

Adidas has also led with innovative, sustainably minded developments in the footwear market. Though they were accused of infringing on Nike's patent (Fashionlaw, 2020), Adidas' Primeknit products have successfully utilized recycled materials and due to the fabric being a knit it creates less waste materials. Adidas also developed an innovative footwear material marketed as their Parley line - that utilized plastic recycled from ocean waste (Moorehouse and Moorehouse, 2017). The shoe was a success and encouraged Adidas to work toward only utilizing recycled plastic in their footwear products. Adidas has also pioneered biodegradable footwear innovations that go beyond CE (Moorehouse and Moorehouse, 2017). Unfortunately, innovation is often a trade secret. As Nike and Adidas pave the way in sustainable advancements, I would argue that their strict patenting and resistance to sharing innovative technology with others has adverse effects on sustainability progression in the marketplace. Education, however, may offer opportunity to push further.

Moorhouse and Moorehouse (2017) argued education plays a key role in stimulating sustainable design innovation. Implementing sustainability in the apparel and footwear industry involves restructuring current production models. Design is a crucial stage of bringing environmental progression to fruition (Deniz, 2016). O'Rafferty et al. (2014) suggested that 
implementing sustainability in design education is crucial for designers to fulfill requirements in the developing sector. Vezzoli (2013) highlighted the importance of implementing sustainability in design education to prepare students to pursue environmental issues effectively (Vezzoli, 2003). A shift in education that encourages designing products with the lifecycle in mind will transfer into what upcoming designers provide to companies. Since then, we have seen research models implementing sustainability into the design curriculum (Deniz, 2016). Though the impact of these shifts in design education have had on the industry are not yet well known, it is essential for design education to prepare students for entry into the footwear and apparel industry equipped to help enact sustainable initiatives. One specific approach education could increasingly emphasize is life cycling thinking.

Evans et al. (2017) suggested that system or life cycle thinking provides companies an opportunity to problem solve and create solutions that influence multiple problems. For this to happen, system thinking requires companies to think across the entire product life cycle. When the whole product life cycle is analyzed, it allows for opportunities for maximum sustainability. Unfortunately, life cycle thinking encounters barriers when manufacturing in the contemporary globalized context. Firms are implementing sustainable initiatives within their corporate structure, but these implementations may not be carried throughout the production process that involves many partners with differing sustainability commitments. Because globalization separates the entities in product development, communication and transparency barriers disturb corporate sustainable efforts (Kumar et al., 2017). When applying system thinking or life cycle thinking, both have the same general meaning of looking at a product's full life cycle to solve problems (Evans et al., 2017). For systems thinking to analyze the manufacturing processes 
completely, manufacturing companies would need to report and track the product's use of resources and resource waste throughout the production across all firms involved. Transparency is a barrier to sustainability, and traceability models are introduced to monitor sustainability initiatives (Marconi et al., 2017). Footwear companies may find it harder to implement system thinking or life cycle thinking to pre-consumer stages considering the vast number of manufacturers and materials required in the process.

Research suggests that systems thinking, and systemic change are crucial for sustainable innovation (Evans et al., 2017). This study aims to use systems thinking to compare the success of companies' sustainable initiatives and how they might be improved. Draper (2015) states that systemic change requires more than one working intervention across a whole system that cannot be changed by a single entity. For sustainable development to be successful, it is argued that major systemic change and innovation must occur (Evans et al., 2017). To add to that, Evans et al. (2017) mentions these innovations "can be more effectively created when building on the concept of business models" (p. 207). This study explores how companies relate their business models to their sustainable initiatives.

Life cycle thinking identifies solutions, sustainable value benefits stakeholders, and multiple value forms (Yang et al., 2014). The first assumption of this approach is that life cycle thinking will provide long-term benefits by focusing on manufacturer and customer relationships. This assumption takes the focus from the beginning of life and looks at benefits acquirable from the middle and end of product life (Yang et al., 2014). Another assumption is that life cycle thinking gives insight into economic, social, and environmental factors (Evans et al., 2017). This insight is essential when looking at sustainable value. Sustainable value is 
created by evaluating stakeholders' benefits in those three areas (Evans et al., 2017). The assumption for sustainable value is that successful integration of sustainability will enhance economic, social, and environmental benefits (Yang et al., 2014). The third assumption is that multiple forms of value exist when analyzing business models. Multiple value concept forms assume that value creation is an opportunity from the value missed and destroyed (Evans et al., 2017). The uncaptured or potential value that lies within a company provides sustainable opportunities. Such value, for example, includes issues like the use of resources (Evans et al., 2017). The SVAT tool delineates the forms of value: captured, destroyed, missed, and value opportunities.

\section{Sustainable Value Analysis Tool (SVAT).}

Life cycle analysis is an important process for companies to successfully implement sustainability (Curwin et al., 2012). In implementing life cycle analysis there are several models that can be employed to examine each production stage to understand where sustainability can be executed. Evans et al. (2017) presented the SVAT to analyze product life stages and determine areas of opportunity. This method guides the users to the opportunities for further sustainable value creation. It is thus a tool to help focus efforts where the most can be accomplished. The SVAT is essentially a guided exercise in LCA. The SVAT model (see Figure 1) breaks down the beginning, middle, and end of life stages of a product along with the multiple forms of value. There are four steps when applying the SVAT tool 1) define the product life cycle; 2) identify the proposition; 3) identify the value uncaptured; and 4) identify value opportunity. The tool organizes the product data and divides it into three areas of stakeholders: profit, planet, and people. As Evans et al. (2017) illustrated in Figure 2, addressing economic, social, and 
environmental factors are crucial when analyzing sustainable benefits. Studies have utilized the SVAT in analyzing the manufacturing of products such as steam turbines and sugar (Evans et at., 2017; Yang et al., 2014). 


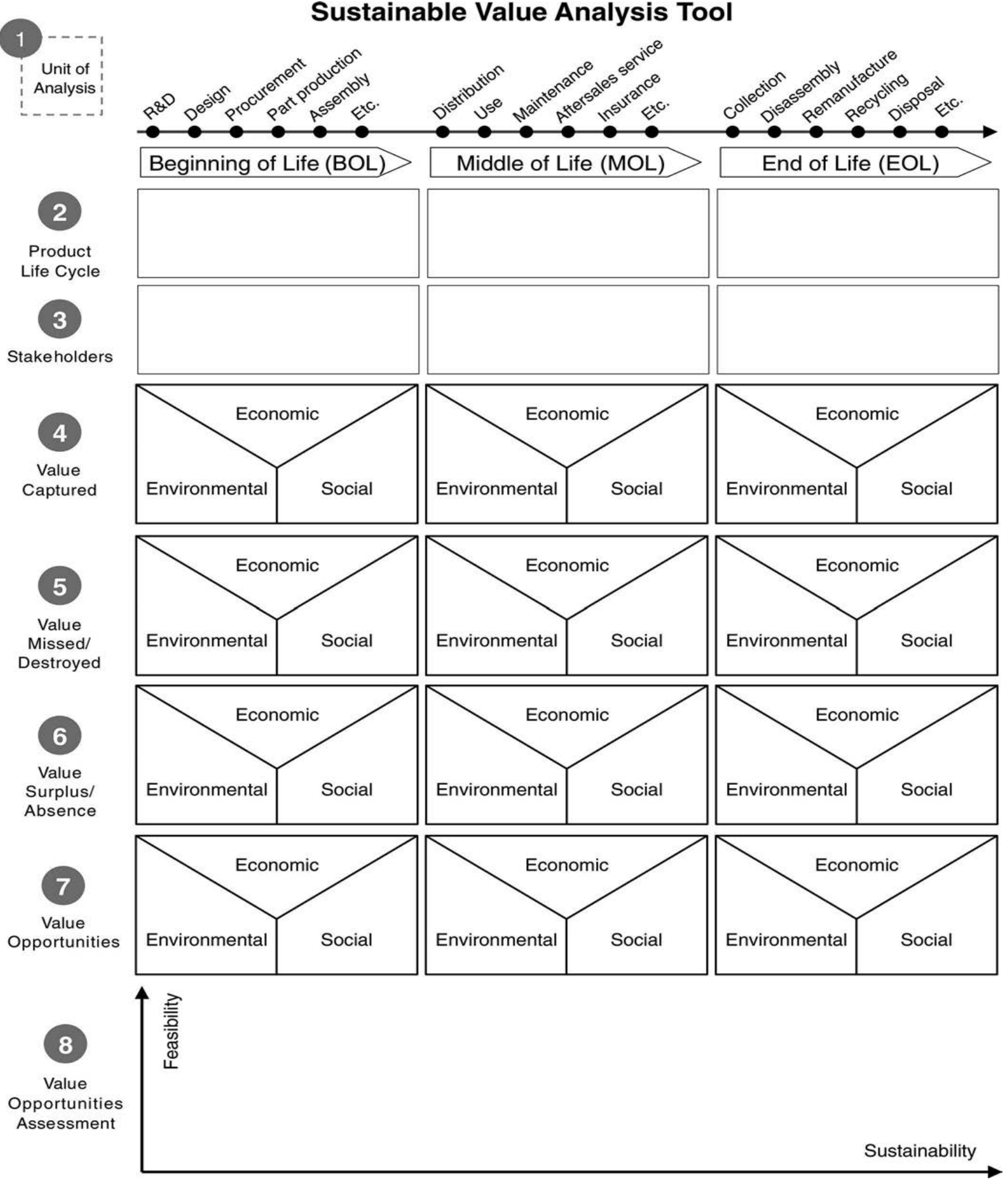

Figure 1 Sustainable Value Analysis Tool. Reprinted with authors' permission from "A Value Mapping Tool for Sustainable Business Modelling" by N. Bocken, S. Short, P. Rana, and S. Evans, 2013, Corporate Governance International Journal of Business in Society 13 (5): 482- 497. 


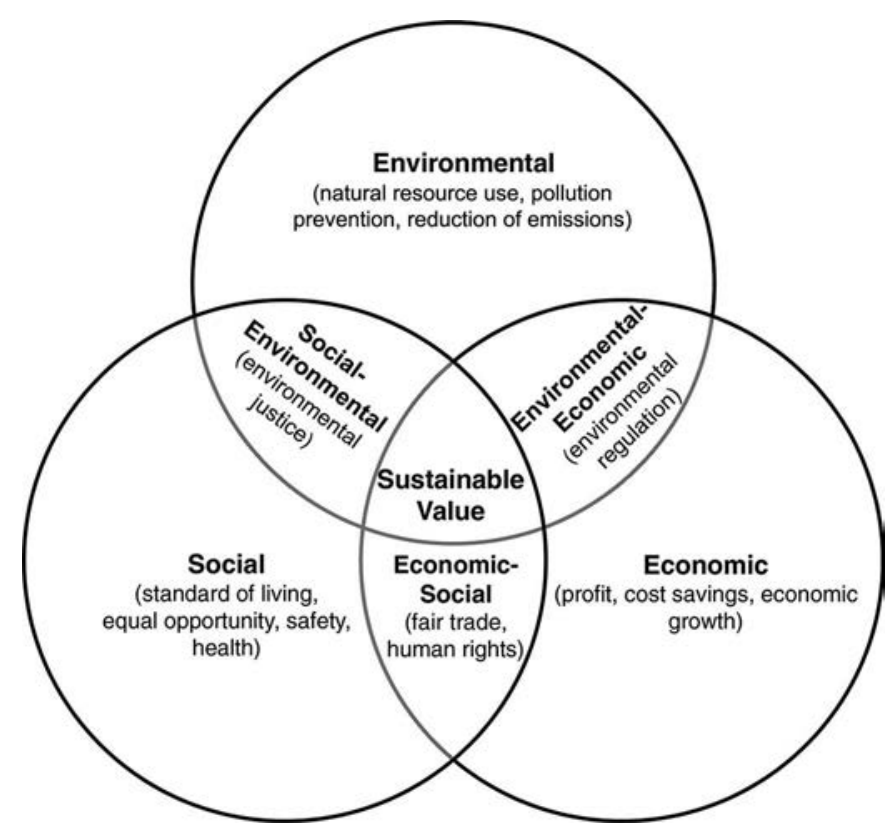

Figure 2 Value Propositions. Reprinted with authors' permission from “A Value Mapping Tool for Sustainable Business Modelling" by N. Bocken, S. Short, P. Rana, and S. Evans, 2013, Corporate Governance International Journal of Business in Society 13 (5): 482- 497.

The SVAT tool provides an outline, guiding users to determine value within a product development lifecycle (Evans et al., 2017). This outline allows for a multitude of findings from insider's perspectives. However, the tool does not provide a strategic way of determining the opportunities (Evans et al., 2017). Rather, this tool's best use is to analyze a single product development process and adjust for companies that provide multiple products. While the tool does not provide specific solutions, it allows for interpretive analysis which aligns with this research study. Through analysis, SVAT can direct where problem-solving solutions should focus. These focus areas do change with each implementation of the tool. The SVAT tool was used to develop the interview questions posed to study participants and offered a point of reflection when analyzing and organizing emergent themes. 


\section{Chapter 3: Research Methods}

\section{Introduction}

This chapter's purpose is to present the research methods used in the study. The first section describes the research methodology and highlights the guiding research question. The second section describes the strategies and protocols used to conduct this study. The third section explains the potential biases and the actions taken to ensure validity within the study.

\section{Research Design}

A qualitative research approach was selected for this study. This approach allowed for indepth exploration of the data through the insight of informants. Qualitative research presents an explanation of a real-life situation through multiple lenses (Yin, 2016). Through qualitative research, researchers can gain knowledge from participants and the meaning they give to their lived experience, to inform their guiding question. This research focuses on participant's placement and intuits to their surrounding world. Qualitative research captures contextual factors that other methods may not provide (Yin, 2016). These contextual factors and insight are gained through interviews with product developers at two companies. In this research, the insight gained through these interviews is applied to a real-world application. This application provides an example that can be applied to other companies. Research suggests that qualitative approaches allow researchers to make sense of a phenomenon by capturing participant's perspectives (Yin, 2016). Baxter and Jack (2008) suggest that qualitative research is resourceful in evaluating programs. 


\section{Phenomenological Research Paradigm}

I will explore the application and effects of sustainable product development within the context of footwear design. This topic called for highly investigative approach that centered on the experience of product developers' lived experience. This study was exploratory, providing the opportunity further insight and knowledge of an under-researched subject. How sustainability is currently and potentially affecting the companies and product developers is unclear. This discovery can provide context for companies involved and other like companies. It would be impossible to understand this phenomenon without utilization of participants within the setting of both footwear companies. Thus, the purpose is to engage participants actively working as product developers.

Interpretivism helps provide further exploration and interpretation of data (Ryan, 2018). While the object is to understand how sustainability affects footwear companies, interpretivism works to understand participants' position within the context. The careful consideration of the participant's positions guides the analysis of data (Khan, 2014). Interviews with participants provided insight into their positions and perspectives. Interpretivism, accompanied with a phenomenological approach, finds meaning within the current situation of Company S and Company $\mathrm{M}$ as well as with those who operate as freelancers. Phenomenology allows for the data analysis to elucidate findings naturally (Wilson, 2015). The study's goal is to understand and uncover. It will uncover the effects of sustainability by interpreting participants' experiences (Ryan, 2018). Using a phenomenological approach aligns with this study's goals. Phenomenology aims to focus on a lived experience produced from a phenomenon and identifies the phenomenon as an object that creates these experiences (Creswell and Poth, 2018). This 
research aims to identify the experiences of employees at two companies and freelancer designers with contracted work in footwear companies that share the same experience of implementing sustainability into the development of a product.

\section{Sampling}

Sampling strategy. Key informant interviews were pursued with active footwear product developers. The initial preference was to recruit product developers and designers fully employed at companies with stated sustainability initiatives. However, initial requests for interviews received just two responses so a less rigid approach was needed to expand the list of informants.

A judgment sample framework was selected to determine a purposeful sample because it ensures the most productive subjects are used (Marshall, 1996). This framework was chosen because it was most beneficial to the study to choose specific informants who have insightful knowledge. According to Creswell and Poth (2018), "participants need to be carefully chosen to be individuals who have all experienced the phenomenon in question" (p. 81). Ultimately, four individuals were successfully recruited into the study; two fully employed individuals sat for extended interviews that followed an established protocol while two freelancers responded to the same protocol but asynchronously via email. This selection included subjects that held positions within product development roles at the two companies as they were relevant to the study topic. The effort was initiated to gather subjects that expressed various perspectives by aligning with the judgment sample framework (Marshall, 1996). Though the sample size is small, the exploratory nature of this study and quality of the responses received provided adequate initial 
insight into the phenomenon, providing fertile ground on which a more comprehensive study could be built.

Once participants were recruited, in-depth interviews were conducted with the practicing footwear developers. Relevant contextual information about their employers as communicated on their respective websites was also gathered and is provided at the beginning of the Findings and Discussion chapter. The aim was to understand the current business model/modes of production and compare how these broad initiatives were conceptualized and enacted by the employed individuals. Participants were also asked their opinions of the sustainable value that is currently captured through the current sustainable motions. Variables such as qualification/ background, status, time spent at the company were used to align with the framework of judgment sampling (Marshall, 1996). These variables help interpret and contextualize the data. This approach aligns with the interpretive framework selected and theoretical approaches that allow the researcher to understand and uncover (Khan, 2014).

Participant overview. Two individuals interviewed for this study worked at companies in footwear product development departments. Two individuals served as freelancer in the industry and were sent interviews due to language and time barriers. The participants were purposefully invited to contribute based on their knowledge and experience (see Appendix D).

\section{Data Collection}

The data collected for this study consisted of two primary sources: interviews with participants and corporate sustainability communications. The documents included publications by the companies on their websites. These documents offered a further understanding of how the company projects itself to consumers and positions itself in the marketplace. For example, 
corporate documents published to their respective websites provided overviews of CSR and sustainability initiatives. These were utilized to gain a better perspective on the corporate context in which the participants operated.

Participant interviews were conducted through a video conferencing app. Participants were in the comfort of their areas of choice, and I was in a-home office. The participant's interview questionnaire was developed in four sections (see interview protocol in Appendix C). The first set of questions allowed the researcher to gain a general knowledge of the participant's experience and role within their companies and the industry more broadly. The second set of questions focused on the participant's general sustainability knowledge within apparel and footwear production and specific sustainable initiatives within the company's footwear production methods. The fourth set of questions were developed with the SVAT in mind. The last set of questions focused on sustainability within production and manufacturing specifications.

The interview questions were open-ended to allow probing for additional information. The development of questions aimed to understand the experiences of the participants. Creswell and Poth (2018) suggest that interview questions should "provide an understanding of the common experience and ultimately provide an understanding of the common experiences of the participants" (p. 79). Once I determined emergent themes after reviewing interview question responses, SVAT was applied to those themes to develop insight on where sustainable value is currently being generated and where there is clear opportunity for further value created. The research represents an outsider's analysis of sustainable initiatives enacted within the footwear product development by individuals with specialized knowledge on the subject. 
The video conferencing app included audio transcription services. These initial transcripts were reviewed, compared to the original recording, and corrected as needed. Each participant was sent a copy of the transcription of the interview. Any edits or additions made by the participants were noted. If any changes were made to the document by participants, the changes were used as the primary source of data analysis. After the transcripts were reviewed, they were stored according to the protocol.

\section{Data Storage}

All data sources, both transcriptions, and video recordings of the interviews were handled and stored appropriately according to the storage protocols. The researcher used a password protected laptop to store data. The data collected included video recording of the interview through zoom and transcriptions provided through zoom. These documents were stored among the researcher's laptop and are planned to be deleted after the defense. No data was transferred into hard copy. Therefore, no documents need to be destroyed. Other data sources included public records of the companies utilized in the study. These sources are appropriately referenced in the research study.

\section{Data Analysis of Findings}

Creswell and Poth (2018) suggest a phenomenological data analysis approach. Their approach includes steps for analyzing the data and, specifically, interview transcriptions. What Creswell and Poth refer to as horizontalization is the first step in data analyses. This step includes highlighting "significant statements, sentences or quotes that provide an understanding of how the participants experienced the phenomenon" (p. 79). From those significant highlights, the researcher then creates "clusters of meaning," resulting in the emergence of themes. Once the 
themes are outlined, the researcher then uses them to describe the participant's experience or describe the influences in the participant's experience, which is referred to as structural descriptions. After the researcher presents the structural descriptions, the next aim is to present the phenomenon's essence, pulling together participants' everyday experiences (Creswell and Poth, 2018).

With these steps, the researcher reviews the data in two cycles. First, the data analyst will go over transcriptions highlighting essential statements. Murray and Chamberlain (1999) suggest "beginning by looking in detail at the transcript of one interview before incorporating others" (p. 220). This will allow for a realistic understanding of themes from the participant's perspectives. The second cycle looks at reoccurring themes amongst all participant's transcriptions. This cycle will enhance the understanding of influences amongst the participant's perspectives.

Understanding the participant's perspective is a critical factor in qualitative research (Yin, 2016). To minimize the researcher's biases, a co-analyst follows the same two cycles to look over the data. This ensures that the researcher's findings align with another view and encourages further findings that the researcher may not have discovered (Creswell and Poth, 2013).

\section{Coding}

In the first stage of coding, I broadly analyzed each transcript for possible codes and themes. I then determined whether the list of possible codes and themes could be grouped. This determined the coding scheme that listed themes. The themes were given numbers for organizational purposes. This coding method was appropriate because "works best in small participant, or case sizes up to ten" (Murray and Chamberlain, 1999, p. 225). Once those themes were determined, I developed a write-up that explained and described general cases and themes. 
The second stage of coding grouped similar themes amongst all the interview transcripts. This included sub-themes, patterns, and relationships. Within the general findings of stage one, I examined specific cases and themes to find patterns. Those patterns and connecting themes were diagramed to "capture the relationships between emergent themes" (Murray and Chamberlain, 1999, p. 232). These coding stages were chosen because they allowed me to look at individual cases and elucidate findings that illustrated a strong understanding of the participant's experience. The second stage then allowed me to connect the findings to understand the interviewees' common themes, which led to an overall understanding of the phenomenon. With this understanding, I could align the coding and analysis findings with answering the research question.

\section{Trustworthiness}

The alignment of the research question and paradigm encouraged the study's trustworthiness. In qualitative approaches, researchers must "ensure the legitimacy of knowledge generated in this paradigm, then you have to demonstrate that meaning and value have been recorded and analyzed holistically and interpreted in context" (Murray and Chamberlain, 1999, p. 219). To ensure the credibility of the data collected, I made the transcripts available to the interviewees for further confirmation and verification. The themes that the researcher identified were subjected to member checking. The themes were also presented to interviewees to ensure credibility. The use of protocols in data collection also contributed to the study's trustworthiness.

Protocols were determined and used by the researcher to guide data collection. Using protocols as a guide created dependable findings from the study. The interview protocol ensured that participants were asked the same questions. The proper procedures and handling of data 
were established to ensure the credibility of the data collected. Ensuring that the protocols were carried out at every step of the research enhanced the study's trustworthiness (Murray and Chamberlain, 1999).

The primary source of data for this study were interviews. The interviews were semistructured and provided descriptive and rich data. Descriptive and rich data is essential to understanding a phenomenon during a study (Khan, 2014). This type of descriptive narratives also allowed the findings to connect to the literature surrounding similar situations and the research question's broader scope. Purposeful sampling was used to ensure that the interviewees had shared the same or similar environments. The use of purposeful sampling best informs the research and contributes to the study's trustworthiness (Creswell and Poth, 2013). During data collection, Creswell, and Poth (2013) suggest recognizing possible field issues to provide accurate data. The Institutional Review Board was utilized before the research to ensure all ethical issues were accurately handled throughout the research.

The potential threats of conducting qualitative research include data sources becoming compromised. That could mean the sources of data are untrue or have created harm through the power imbalance of the interviewer and interviewee (Creswell and Poth, 2013). A pilot interview was conducted to ensure that the questions align with the research and do not cause harm to the interviewee. Another potential threat is the data collection for the study does not align with the literature and theoretical perspectives. The literature review for this study gives a strong background and guides the research to ensure credibility. Qualitative studies involve the researcher and their position within the research. This could become a potential threat to the trustworthiness of the study. The researcher's biases are made known in the next section to 
enhance credibility. The researcher's position will also be made known to limit the potential threats of bias.

\section{Positionality Statement}

The researcher's positionality comes from their worldview, including the individual's values and beliefs (Holmes, 2020). Positionality is how the researcher represents themselves within the research and can influence the study's process and results. Creswell and Poth (2018) explain the importance of describing the researcher's role within the study to add credibility by "writing about own experiences and the context and the situations that have influenced their experience" (p. 80). This allows for the researcher to identify their role within presenting the essence of findings. Thus, a research can use positionality statements to simultaneously embrace the bias inherent in all research while still maintaining full transparency in the process.

My background begins with an undergraduate degree in fashion design. During my undergraduate course work, I enhanced my design focus by formally and informally learning more about sustainability in the industry. I took great interest in the devastation the fashion industry poses on the environment. From that, I utilized my coursework and projects to learn ways of initiating and implementing sustainability in both design and merchandising classes. This allowed me to gain a strong understanding of barriers and issues the apparel and footwear industry faces when implementing sustainability. I also understood what it takes for a company to be completely sustainable and the benefits that come with pursuing such ends.

Furthering my education, I pursued a graduate degree at West Virginia University. I held a graduate research position during my thesis-based master's coursework. Again, I focused on sustainability through my research, working alongside faculty. I assisted with establishing a fiber 
shed for the Central Appalachian area. I gained insight into networking and understanding how natural fibers are currently being produced and the opportunities that lie within networking and connecting natural fiber sources. My previous research study was sustainability-based and contributed to my knowledge of sustainability in the industry. My background positions me in the current research study. From my experience, I can connect with the participants for this study and share common knowledge of apparel and footwear design and sustainability. 


\section{Chapter 4: Findings and Discussion}

\section{Introduction}

Interviews with individuals actively engaged in the footwear product development process at corporations known to engage sustainably-minded initiatives were used as primary data sources. Interviews with individuals working in the industry as freelancers specializing in footwear design provided additional data. All together the informants provided insight into their experiences enacting sustainable initiative in footwear product development. It was found that informant's definition of sustainability differs from the all-encompassing definition that includes environmental, social, economical concerns. All four informants expressed environmental concerns as their focus in sustainable initiatives and limited focus for social impacts. The findings highlight themes found through analyzing the data sources. These themes include two main sections: Domains of Influences and Limitations. Domains of influence explores areas where informants had the most power and opportunity. Those areas included materials selection, life cycle analysis, and communication. Limitations were found internally and externally amongst informants. Internal themes of limitation included consumers, material scarcity, manufacturing partners, and design process. Themes of external limitation include corporate pricing structures, goals vs. reality, and life cycle analysis.

\section{The Product Developers and their Context}

Informants for this study included four footwear product developers. Of the four footwear product developers interviewed, two were fully employed, and two served as freelance designers. The pseudonyms Chloe, Sierra, Austin, and James will be used as pseudonyms. See Table 1 for a condensed summary of informants' backgrounds and current industry position. 
Table 1

Summary of Participants from Footwear Product Development

\begin{tabular}{|c|c|c|c|c|}
\hline Position & Pseudonym & Employer & $\begin{array}{l}\text { Years of } \\
\text { Industry } \\
\text { Experience }\end{array}$ & $\begin{array}{l}\text { Years with } \\
\text { Company }\end{array}$ \\
\hline $\begin{array}{l}\text { Product Developer/ } \\
\text { Sustainable Task } \\
\text { Force }\end{array}$ & Chloe & Company S & 11 & 4.5 years \\
\hline $\begin{array}{l}\text { Director of } \\
\text { Sustainability/ } \\
\text { Product Development }\end{array}$ & Sierra & Company M & 6 & 3 months \\
\hline Freelancer & James & N/A & 2 & N/A \\
\hline Freelancer & Austin & N/A & 2 & N/A \\
\hline
\end{tabular}

For those fully employed, their places of employment are referred to as Company $\mathrm{S}$, and Company M. Chloe had been employed as a product developer at Company S for four and a half years. She has been employed in the apparel and footwear industry for eleven years. Company S is a footwear company headquartered in Denver, Colorado with manufacturing activities located offshore. Company $\mathrm{S}$ is considered a large enterprise considering their sales data and employee numbers (SANGOMA, 2021). The company is recognized for producing innovative products developed for different climates and outdoor activities. Company S's footwear sector produces multiple styles such as running sneakers, hiking boots, sandals, and slippers. Their outdoor styles focus on providing quality, durable and functional footwear for their consumers. While Company S provides sustainability initiatives, the company does not attach sustainability as a mission or label itself as a green or sustainable brand. In 2000, Company S was purchased and became a conglomerate. Under the new corporate umbrella, Company $\mathrm{S}$ and others were tasked with reaching sustainability goals set by the corporation. In response, Company S developed a 
sustainable subcommittee on which Chloe actively participated. The subcommittee considers how and where to implement sustainability initiatives to reach their corporate goals. These corporate goals include $\mathrm{X}$ number of products made entirely of recycled materials, circular design, and sustainable packaging. All these goals are set to be met by the company in 2025 , what Chloe considers the 'milestone year.' Chloe mentioned these goals mainly focus on the company's carbon footprint.

At the time of the interview, Sierra had recently been employed at Company M serving as director of sustainability for three months. She had worked within sustainability-related roles in the apparel and footwear industry for six years prior. Sierra's role as director of sustainability entailed working directly within product development in both apparel and footwear sectors at Company M. Even though Sierra's time at Company M had not been long, she has been directly involved in the execution of sustainable initiatives, thus making her an ideal informant for this study. She focused her responses explicitly on her role within the footwear sector at the company. Company $\mathrm{M}$ is an apparel and footwear company headquartered in the San Francisco, California with manufacturing operations located offshore. According to SANGOMA (2021) Company $\mathrm{M}$ is considered a small and medium enterprise (SME). The company is recognized for providing ethical products and attached the term ethical to their brand's mission. The company instills ethics into every product by providing statistical data on the product. This data includes laborers and resources used to make the product. Company M does manufacture their products globally. The company provides all their manufacturing facilities locations and information on their website. Company $\mathrm{M}$ is accredited by its consumers for their transparency. Their footwear 
sector provides casual and dress shoes for men and women. Sierra works amongst the rest of the footwear product development team as a guide for sustainable initiatives.

James and Austin are freelance designers within the footwear industry. James worked as a freelancer for two years and has worked as a team lead for his "mini studio design." Austin has also worked for two years as a freelancer in the footwear industry. James has worked as a team lead on his mini studio designs for six months. Both James and Austin specialize in footwear design. Austin worked for what he considered 'micro companies' while the size and type of companies James's mini studio provide designs for was undefined. Austin and James are both located outside of the US; this resulted in some language and time barriers during the recruitment process. As a result, interview instruments were sent to both freelancers through email, where they provided as much information as they could to answer the questions. Austin and James provided insight into how footwear freelancers in the global market respond to sustainability.

\section{Defining 'Sustainability'}

Sustainability within this study's context refers to initiatives contributing to lessening a product's negative environmental impact. Jacques et al. (2010) found this definition frequently used in initiatives in the apparel industry. These initiatives include any alteration to the current model of production with environmental intentions. Moon (2013) claimed that nothing could be deemed fully sustainable due to the complexities of global supply chains and production models. As a result, the term sustainability is frequently misused amongst the apparel and footwear industry (Curwin, 2012). For this study, sustainability is used as an overhead term defining the mission companies work toward, not an end goal. It was found that informants operationalized sustainability by prioritizing environmental initiatives. Thus, the use of sustainability in the null 
encompassing term was a theme found amongst informants. For Sierra and Chloe this could be because of influences of their corporate structures as they both aim to reach stated goals by the company. Due to their positions within the companies, they may not receive full communication of the companies' social concerns and initiatives as they may not apply to their abilities. As a result, the informants showcased their environmental efforts as they are the most familiar with those initiatives.

Chloe was unsure of her companies' social policies and efforts during the interview. Throughout the data analysis it was found that she did not mention any consideration of social impacts within her role. Though she did mention in her review of the transcript that the company is recently starting to implement agreements with their factories and vendors that ensure they are aligning with their sustainability mission. While Chloe did not participate in these new measures it is found that the company has recognized ethics as a part of their sustainability mission. Chloe explained, "included in sustainability standards are also ethics, meaning minimum age requirement for factory workers, reasonable working hours (no obscene overtime), healthcare, proper working conditions, exit routes on the factory floor, etc."

Both Chloe and Sierra talked about labor and social impacts in terms of corporate initiatives focused on improving the lives of workers. For Chloe, these initiatives were out of her role to be able to impact. Sierra portrayed performing on Company M's social initiatives as not a part of her primary role but did express that she held strong relationships with their manufacturers. Both explained that their social initiatives were set in place to align with the companies' overall missions. From this, it can be observed that labor and social impacts are not prioritized in their product development roles. Though it was found that labor and social 
initiatives are dependent upon the mission of the company's business model or corporate mission. This aligned with Jacques et al. (2010) statement that companies with sustainability in their business model place importance on their manufacturers. Therefore, since this study utilized the lens of product developers the definition of sustainability used throughout diminishes social and economic impacts.

\section{Domains of Influence}

Domains of influence was an emergent them to capture how where informants felt the most power to execute sustainability. Informants presented areas of opportunity for sustainable progression within their power. These opportunity areas included materials selection, life cycle analysis, and communication. It is important to define where product developers can execute sustainability to understand further how sustainability efforts decreed at the corporate level affect footwear product developers. The position of each employed interviewee's companies differ in incorporating sustainability amongst their business models. This differentiation illustrates the importance of corporate context to the interviewees' ability to execute sustainability in product development.

While designers provided concepts for footwear products, Chloe expressed that her role as a product developer is responsible for bringing the design to life. Materials selection is one key part of that process. Chloe and Sierra explained how materials selection is a notably vital opportunity to initiate sustainability within their roles. Footwear product's material make-up contributes to negative environmental impact (Jacques, 2010). Both acknowledge this and seek to find alternative sustainable materials such as recycled polyester, recycled plastic, recycled rubber, organic cotton, leather, and other natural and synthetic materials. 
For example, when looking at leather as a material commonly used within the company's dress shoe styles, Sierra considers leather a problematic material. While leather is a byproduct of the meat industry - and thus puts a waste product to good use - processing leather also requires harmful chemicals. Sierra explained,

When we look at it from the life cycle assessment - so for everything from the land use to the carbon emissions to just the trajectory of the global supply chain - the chemical usage and water impact - it's a little bit problematic. So, we've done what we can within our supply chain to source from suppliers who are part of the leatherworking group, so we source from suppliers who are already utilizing safer chemistry practices.

Here Sierra described that working with the Leather Working Group allowed her to control the leather she sourced. The Leather Working Group is a non-government organization (NGO) that certifies leather manufacturers to regulate the negative environmental impact of the leather industry (Leather Working Group, 2021). As a result, working with the group gave Sierra's role more power to source within the leather supply chain consciously. This power is essential when looking at how Sierra's role was impacted by globalization.

Kumar (2017) suggested that globalization has created a shift in responsibility for sourcing, leaving buyers - in this case, product developers - responsible for ensuring that they are sourcing ethically. Sierra was able to utilize NGOs to navigate the global market and responsibly source leather. Though, leather only applies to a fraction of materials used in Company M's footwear products, Sierra's efforts to source more responsibly positively contributed to the overall environmental goals of the company's footwear production. The efforts 
also contributed to reaching broader goals presented by Company M. These goals include providing quality and transparency to consumers in their products.

More significant sustainability goals set by Company S and Company M were reflected in Chloe and Sierra's roles of materials selection. Chloe mentioned that a goal of Company S's was to have "X amount of projects to be $100 \%$ recycled." She recognized that her role in materials selection was an essential contributing factor in the success of this goal. For example, Chloe successfully integrated recycled polyester across all styles of the brand's footwear uppers that used polyester. Both Sierra and Chloe mentioned recycled polyester as a common material used to reach footwear sustainability goals since it is a suitable material for uppers. Chloe stated, "I'd say polyester is our number one material used on a footwear upper." At the start of Sierra's role within Company $\mathrm{M}$, she was able to source recycled polyester laces as the standard for all footwear. She also successfully sourced recycled polyester to replace current polyester textile uppers. Both transitions positively contributed to the company's sustainability initiatives.

Though the increased use of recycled materials was seen as a big accomplishment for both informants' supply chains, there were noted performance issues. This was the case for both Chloe and Sierra. Chloe aimed to incorporate as much recycled polyester as she could into products to reach their corporate goals without affecting the product's performance. She worked within her role to better understand the material make-up and purpose of their footwear products. From this, Chloe found an opportunity within her power to strategically incorporate recycled materials without degrading the overall performance. Chloe explained,

We basically have two categories performance run like trail run and hike and then lifestyle, which would include like insulated cold-weather gear, as well as like sandals 
and that side of the business kind of piggyback on what I was saying about the performance it's a lot easier to put sustainable materials in that lifestyle bucket just because consumers aren't expecting to climb mount Everest in a sandal you know so it's okay it breaks down or even if it just doesn't last as long.

By considering the needs of their consumers and the intended use, Chloe and the product development team strategically reached their company's goals. Moving forward, Chloe hoped to continue this strategy of increasing recycled materials in lifestyle products. Chloe utilized an opportunity she found within the immediate power of her role amongst materials and design that resulted in success.

Material sourcing and integration into footwear design of footwear products illustrated in this section as influential roles for Sierra and Chloe to initiate sustainability. Though Sierra mentioned that she and Company $\mathrm{M}$ only contribute to a portion of the overall footwear industry, their efforts are a proof-of-concept larger corporations can employ. Chloe also pointed out that Company S does not largely contribute to the overall footwear production but actively works toward sustainable innovation. Sierra, Chloe, and Austin offered Nike and Adidas as companies leading innovation and sustainable progression. Sierra and Chloe expressed hopes that as Nike progressed that they would begin to 'normalize' sustainable thinking within the industry. They both reflected Nike having the ability to change the way the industry thinks about sustainability through innovation. Chloe expressed "needing Nike to do it first." Nike normalizing 3D modeling would enhance her ability to progress $3 \mathrm{D}$ modeling as a standard procedure in product development at Company S. Chloe's statement illustrates the importance of knowledge sharing and education in sustainable initiatives. As other scholars have noted (Moorehouse and 
Moorehouse, 2017), knowledge sharing is essential step if the industry is to reach their sustainability goals. Nike's unwillingness to share information amongst the industry was displayed as a barrier. Here, Sierra and Chloe both hinted to Nike as leading the industry and holding power to enhance their abilities through information sharing, supporting the literature.

Evans (2017) has suggested product life cycle analyses (LCA) are also essential to reach sustainability goals. LCA is a standard method for identifying opportunities for sustainable development within a product. To successfully apply LCA to a footwear product, the beginning of life (BOL) logistical data is provided by tracking the resources and material used throughout the manufacturing process. Both companies included in this study operate in the globalized market. Globalization is suggested by Marconi (2017) as a barrier in initiating sustainability due to the complexity and lack of transparency in the global market. While LCA is hindered by globalization, Sierra and Company M successfully work with their manufacturers to provide analytical data on their footwear products manufacturing process. In fact, a key aspect of Sierra's role is to ensure continued relationships by working closely with manufacturers. With the data gathered from her close working relationships, Sierra can perform LCA on all their footwear products. LCA provided Sierra the ability to track the success of sustainability initiatives and determine her material selections had on a product's overall environmental impact. This type of analysis is what led Sierra to discover the impact of their leather footwear products. Sierra explained, "From life cycle analysis that we have done on our own product that there's an immense amount of waste in the leather supply chain from just from processing to the end product." Company M's ability to provide logistical tracking of their products enhanced Sierra's 
ability to execute sustainability initiatives by giving Sierra some control within the supply chain and guide focus on other problem areas.

Application of LCA breaks a product's life down into stages, beginning, middle, and end. Analyzing a product's stages allows for guidance toward where sustainable implications are most needed. Footwear's BOL and EOL reflect the most environmental concern (Jacques, 2010). Footwear BOL includes manufacturing stages and procurement of raw materials and components that are ill-tracked. The EOL stage is criticized for the mass disposal of products that contribute to overall environmental pollution. Circular design is the process of creating products to be recycled or regenerated at the end of their useful life. Designing a product for recycling at EOL was mentioned by Chloe, Sierra, and James as sustainable initiatives that could have real impact. Chloe stated,

Our biggest goal would be to have circular products, something that the consumer buys, and then it can either be remade into the same thing, or it can be like planted and composted or something that just completes the life cycle or continues.

Though, she recognized circular design as a sustainable initiative able to be executed within her role, Chloe did not express any progression on implementing the practice. Sierra shared that Company $\mathrm{M}$ has a circular design footwear product that they produced and were actively selling to consumers. The footwear product had not matured enough amongst consumers to reach its EOL stage, however, so the full concept had yet to be proved in practice. While Sierra was not a part of the product development for this specific product, she recognized it as a sustainability initiative applicable to more than just one of the company's footwear products. She expressed hope that Company M would continue applying circular design throughout all their footwear products within her role. James mentioned designing products to be recycled as a sustainable 
solution for the waste but did not act upon the design method. This could be due to limitations within his role as a freelancer, as his main duty is to produce within outside structures.

The success of sustainability initiatives is partly reliant on encompassing all entities of the product's lifecycle (Curwin, 2012). The previous section briefly highlighted the communications role in implementing LCA, as Sierra was only able to gain insight on leather's negative impacts through close communication with her manufacturing partners. Communication is an essential factor to successful supply chain management and LCA. A diverse array of groups including product developers, manufacturers, sourcing agencies and consumers among others must share information for sustainability initiatives to succeed (Kumar, 2017). Communication was a theme across Sierra and Chloe's conversations as they explained executing their sustainability strategies. Sustainable subcommittees were established in both Company S, and Company M. These subcommittees provided a platform for employees to communicate in a space focused on sustainability. Communication in this setting enhanced Sierra and Chloe's ability to spread ideas amongst employees. For example. Chloe discussed a challenge she experienced within the subcommittee, her inability to provide consumers any form of logistical data to defend the addition of recycled material to footwear products. She recognized that the challenge inhibited the effective presentation of sustainability initiatives to consumers. Once Chloe communicated the challenge, members of the subcommittee provided their expertise and developed a solution. Further, Chloe expressed hope that the success of this initiative will progress their ability to track materials and product life cycle within the product development team. These findings revealed how Company S's internal communication affected their ability to meet sustainability goals. 
A similar situation presented by Sierra expressed success in her ability to communicate externally with manufacturers. Communication of sustainability initiatives with consumers is a mission of Company M. The success of this mission is reliant on their relationships with manufacturers. Sierra stated,

For our footwear, we are currently manufacturing all overseas um and I think no matter any product, a close and open and transparent relationship with your suppliers is key like must happen for any kind of sustainability initiative to take place.

Jacques (2010) suggested that communication and relationships become more natural for companies that consider sustainability in their business models. Sierra's experience further illustrates this assertion. Company M's business model considers sustainability and aligns with manufacturers and sourcing agencies with similar values. As a result, Company $\mathrm{M}$ has provided Sierra with consistency between the company and their manufacturer's values, which enhanced her position. Even though Sierra was new to the company, she had a strong line of communication with offshore manufacturers. Sierra stated, "We come to them with ideas sometimes; they come to us with ideas.” The relationship enhances Sierra's ability to communicate and implement sustainability initiatives with manufacturers. In contrast, Chloe's role in communicating sustainability externally was hindered due to the lack of direct relationships with manufacturers.

\section{Limitations.}

It became clear during data analysis that informants were struggling with a variety of limitations that hindered their ability to execute sustainability initiatives. These elements included external and internal influences. External influences included consumers, manufacturers, materials, and the design process. Limiting themes amongst internal influences 
reflected the corporate pricing structures and the company's traceability into the entire supply chain. This section explores each of Chloe and Sierra's positions within their corporate structures. Their corporate structures were found to contribute to how and where they felt hindered.

Moving forward, it is essential first to further define each company's consumer base. Company M provides their customer with logistical data on elements of each product's environmental and ethical standing. Kumar et al. (2017) suggested that this is appealing for conscious consumers and encourages brand trust. Company S cannot provide the same type of logistical evidence due to their lack of traceability in their supply chains. As a result, Chloe presented the challenge of gauging how much their consumers are willing to pay for more sustainable products. Company S tried to gauge willingness to pay in their apparel sector by providing a higher-priced recycled garment collection. At the time of my conversation with Chloe, Company S did not have enough data to determine consumers' response to the price increase for the more sustainable option. Chloe attempted to enhance consumer's willingness to pay through the same tactic Company M has successfully implemented: by providing logistical data. However, Chloe's ability to do this was hampered by her limited access to the company's product supply chains. Limited access became a problem when justifying the price increase that comes with utilizing recycle materials. When seeking alternative materials Chloe and Sierra both noted the price increase for recycled materials, which ultimately required price increases on products that used recycled materials. Because Company S's consumer response to the price increase was unclear, Chloe's power to incorporate more alternative and recycled materials in their footwear products was hampered. Though both Chloe and Sierra noted the price increase for sourcing recycled materials, Sierra did not experience this issue with their consumers. This 
could be because of the company's transparent supply chain and background of providing their consumers with logistical data on their products ethical standing.

When sourcing materials Chloe and Sierra both stated that quality, durability, and cost where key in determining which material were selected for production. Quality and durability became a theme when navigating recycled materials and limited their abilities to source materials. Chloe explained,

Where it gets tricky is the bottom unit so like the midsole and the rubber, and that makes up the majority of that. Sometimes there is some plastic or whatever, but um those materials are just harder to come by recycled, because it really impacts, the performance. The available materials did not provide the same standard of quality and durability as nonrecycled rubber and plastic. Company S specializes in gear for outdoor activities where durability and quality are critical. The lack of durability in recycled plastics and rubbers created a challenge for Chloe when trying to achieve Company S's goal to produce more recycled products. Sierra expressed a similar experience with her sourcing options when it came to plastic and rubber materials. Sierra explained,

You can't get $100 \%$ recycled plastic for a lot of these structural pieces of footwear so we start to add percentages in at a time so that we don't compromise the overall durability or performance of the product that we're making because you still want to make a great durable and long-lasting product that people can use, but we can't replace materials out and degrade what the performance of what the product is.

There was minimal accessibility to alternative plastic and rubber materials that passed both Company M and Company S's durability and quality standards. The lack of qualifying materials - due to the degradation of plastics and synthetic rubbers when recycled (Jacques, 2010) - 
limited Sierra and Chloe's efforts in redeveloping footwear bottoms. While polyester has been successfully integrated where performance and durability are not essential to the design, plastic and rubber make up the most structural components in the design. Therefore, placement of recycled plastic and rubber in the bottom of footwear products required a less-sustainable approach, one that did not compromise performance.

Chloe and Sierra both lamented the lack of recycled material options available in the marketplace. Chloe expressed that she felt like her ability to source materials was limited due to sustainability being a new focus for their supply chains. Sierra similarly expressed that the newness of sustainability hampered her efforts to minimize material waste. When discussing her LCA of leather components in Company M's footwear, Sierra explained,

I was very shocked when learning what the wastage yields were because it is so much higher than it is in apparel and for apparel, there has been a lot of work done on building patterns and cutting to really minimize the material wastage and in footwear, I feel like there just has not been that side of the industry has not caught up I would say or maybe there has not been as much focus.

Wastage yields in the leather footwear products specifically became an uncontrollable factor for Sierra, even with her close partnership with manufacturers. Material waste is produced in the manufacturing stages of footwear development and contributes to footwear's overall negative environmental impact (Curwin et al., 2012; Murray, 2002). This waste is produced from cutting patterns for footwear designs. James confirmed, "I often see waste from shoe companies such as the rest of the upper, the rest of the sole, the reject shoes, and many more, but I hope the waste problem can be resolved." 
Wastage yields in the footwear industry have been tackled through innovations such as Nike's regrind. Sierra and Chloe both expressed interest in Nike's waste solutions. Chloe expressed hope in eventually working with manufacturers to incorporate their waste elements into an appropriately recycled material. As of now, she is limited in her access to effectively executing this initiative within manufacturers. Chloe also mentioned that Company S's lowervolume orders compared to other footwear brands contributed to her limited ability to implement change. Though Company M portrays similar order volumes, Sierra did not note this as a limiting factor. Instead, Chloe's limiting factor could not be that of order volume but the lack of sustainability within the business model or Company S's relationship/communication with suppliers. From an outsider perspective, Company $\mathrm{S}$ has more work to do in aligning corporate sustainability goals with supply chain practices. Company M's supply chain practices, however, are more in line with their goals, reducing - but not eliminating - barriers to implementation of more sustainable supply chain practices.

Chloe mentioned several times a sense of limited power to execute sustainability within the company. An internal conflict between her vision and the product development team frequently occurred when presenting footwear products to meet the expectations of the corporate structure's sustainability goals. Chloe explained,

When you have a brief, it is like we want like you know the best level sustainability product here, but we want to make it like a $\$ 20$ FOB (Free on Board, total expense of the product). We have FOB target, and we have margin percentage targets every season and so that goes back to the sustainable materials costing more like the category manager wants it, but then the price comes in, and they're like, well, can you make it better? 
Chloe was able to do everything in her power to execute sustainability within the footwear products as desired by corporate goals but was limited when meeting the companies' targeted FOB. Corporate entities did not adjust their corporate pricing structure to align with their sustainability goals resulting in a constant conflict. Chloe stated,

I'm like not really like this is kind of it is what it is, do you want it or not, and then you have to start peeling away the sustainability that they originally wanted because they can't afford it so I think, maybe back to that question about where it's failing in the industry is the access to the materials like to be able to build something at a comparable price, I mean you just can't right now and that really does impact the success of like sustainable. This internal conflict limited Chloe's ability to execute sustainability successfully. Again, the lack of alignment with sustainability in the corporate structure led to a barrier for Chloe. The conflict represented the expectations of the corporate structure versus the reality of implementing those goals. While Company $\mathrm{S}$ is eager to produce more sustainable products, its current corporate structure does not support the necessary adjustments. Although Chloe faced more internal limitations due to the company's corporate alignment with sustainability compared to Sierra, they both expressed similar barriers when discussing external factors affecting their enactment of sustainability.

Other barriers Chloe faced when executing sustainability occurred from her role within the company. Chloe and Sierra both felt incredibly responsible for initiating sustainability, although successful execution requires contributions from all entities. Sierra's role as sustainable director allows her to focus on sustainable advancements within product development. Chloe's role differs because she is only a member of a subcommittee. She expressed that sustainability was hindered because it was viewed as a secondary role, with the primary roles as product 
developer. Thus, Chloe felt she was a product developer who must also consider sustainability as opposed to a sustainable product developer. Chloe stated,

It is like we're doing our day job and we're also trying to figure out the sustainability stuff like we need like a huge team like if we want a QR code, I think that's a great idea if we want that to actually execute, we need someone to like to be dedicated to that not like you know, part two of their job.

While Chloe and her team are discussing new ways of executing sustainability, their roles are limited due to the secondary nature of this subcommittee. The inability of product tracing hindered Chloe's role due to a lack of corporate alignment. Traceability is notably an important factor in executing sustainable initiatives within the global market, yet Company S's corporate structure has yet to offer an investment into the opportunity. Therefore, while ideas for overcoming the barrier have been presented in subcommittee, execution was hindered. Chloe mentioned that one role would have to be dedicated to the execution of a QR for success. Jacques (2010) found that product development teams across the footwear industry are hindered in sustainable execution due lack of investment from companies.

Though the primary focus of Sierra's role is sustainability, and she operates in a corporate environment willing to support sustainability initiatives, she expressed success depends on all stakeholders in the products BOL. Sierra stated, I feel like the sustainability community is really focused on the topic and I feel like we are always forced to solve the problem, but it really must be a much wider group of people it has to be designers, developers, supply chain partners both upstream and downstream to really make something like that come to life. 
Sierra's statement aligned with Curwin's (2012) suggestion that sustainable design encompasses alignment throughout all members contributing the products life. Sustainability as both primary and secondary roles are presented with limitations. While Sierra's position was better supported by her corporate environment, she still faced barriers in the external stakeholder community. Without alignment amongst all entity's limitations hinder the success of sustainability. SVAT.

Aligning the interview questions with the SVAT guided this study to discover sustainability and apply the following terms found in the SVAT: value captured, value uncaptured, and value opportunities. The SVAT breaks down products into stages of its life cycle to analyze their environmental impact. The stages are then evaluated to define where sustainable value is captured, uncaptured, and opportunities that come from uncaptured sustainable value. Sierra and Chloe expressed focusing on the lifecycle of footwear products in stages to guide sustainable goals. The SVAT aligns with their focus by illustrating all of a product's life stages. This section separates into the beginning (BOL), middle (MOL), and end of life (EOL). Each section will provide examples from participants that align with the SVAT to illustrate how and where each product developer, and by extension, each company, is enacting sustainability. Further, it illustrates where each could potentially reap more value with alterations to their product development processes.

BOL. Sierra, Chloe, and James expressed material waste as a BOL focus area for executing sustainability. Sierra stated that Company M could track and gather logistical data on their footwear products' BOL stages and allowed them to apply life cycle analysis on their products. As a result, Company M could track their sustainability initiatives' success, providing an example of value captured in the BOL. Company S could not follow their footwear products' 
environmental impact during the BOL. Chloe expressed that the lack of logistical data on their footwear product BOL hindered sustainability initiatives' success. The lack of logistical data at Company $\mathrm{S}$ is an example of value uncaptured. An example of value opportunities for Company $\mathrm{S}$ is that with the ability to track their footwear product so they can analyze and gauge their footwear products' overall environmental impact. While Chloe discussed the successful application of a formula to accurately present percentages of recycled material utilized in a design, her ability to move forward is limited. The limits of the SVAT can be discussed here since knowing the opportunities and being able to enact them are different things entirely. Due to the lack of alignment between Company $\mathrm{S}$ and its supply chain, Chloe feels unable to implement further change. She could potentially seek manufacturers and vendors in the supply chain with sustainable goals but cannot guarantee support from the company. Her role here is inhibited from making change without reassurance from the company. As presented earlier, Company $\mathrm{S}$ is unwilling to modify their FOB targets and contributed to value missed.

MOL. Consumers and consumption are focus areas that both Sierra and Chloe expressed in their footwear products MOL. Sierra and Company M successfully provide consumers with data on their footwear products' environmental impacts leading to brand trust creating value captured. Chloe expressed concerns about not building brand trust with Company S's consumers because they have no data to back up their claims. Specifically, they could not provide the percentage of recycled material in their footwear products resulting in value uncaptured. In response, the company addressed the value opportunity of delivering this statistic to consumers and created a formula. This formula provides an accurate reading of the percentage of recycled materials used in footwear products. Evans (2017) presented "under-utilized assets" as the missed value in terms of the SVAT. Chloe's communication amongst the sustainable 
subcommittee revealed missed value in the underutilization of employee's abilities. Chloe's communication amongst the subcommittee led to turning missed value into an opportunity that resulted in successful communication with the consumer base.

EOL. Chloe and Sierra expressed circular design as a focus area for their footwear products. Company M had successfully designed a sneaker that can be broken down at EOL and recycled. This design created value captured in Company M's sustainability initiatives. However, circular design represented value uncaptured for Chloe and Company $\mathrm{S}$ as they have not yet successfully applied circular design. Although this value is currently uncaptured, Chloe expressed interest in the circular design opportunities. These value opportunities include a way to manage material usage and lessen their footwear products' environmental impact. Her ability is limited, though, in initiating the design process for circular products. She can contribute to materials selection and oversee procedures for EOL once they are in place, but cannot design her product.

The SVAT provided an additional lens in exploring the participant's dialogue by organizing their experiences into 'achievements' and 'opportunities'. Though, the complexity of the footwear industry and the global supply chain did affect how well the SVAT aligned with the participant's discussion. The most effective part of the SVAT for this study was the separation of a product's beginning, middle, and end of life. The separation of these stages led to an understanding of where companies are executing sustainability initiatives and where barriers are most occurring. Thus, it has offered a clear and concise view of where each company, with the aid of their product developers, can proceed in sustainable value creation. However, the broader context of the global supply chain must be considered here as it may hinder any action on potential opportunities identified by the SVAT. 


\section{Chapter 5: Conclusion}

I explored the engagement and execution of sustainable practices in the footwear industry. Footwear product developers provided direct access to their working processes, illustrating the enactment of sustainable initiatives promoted by their employers. The SVAT helped the study's framework elucidate findings in terms of sustainable value (Evans et al., 2017). Evans (2017) suggested that the SVAT can determine opportunity areas within the product life cycle for initiating sustainability and placement. When the product life cycle is broken down into stages, their results allowed for a stronger understanding of the power and limitations of product developers. In this study, sustainability in the footwear industry gained context through interviews with product developers. The in-depth interviews with two employed product developers provided insight into how each informant was tasked with sustainability. Immediately it was observed that Chloe and Sierra's power and limitations reflected their companies' business models. Their insight provided how sustainability was being engaged at a corporate level within their companies. At the same time, their roles gave insight into the execution of sustainability within product development. Freelancers Austin and James reflected how product developers' that work outside of a company structure engage and execute sustainability initiatives. Because their interview insight into manufacturing and product development was not as vast as Chloe and Sierras, their dialogue became complementary in the findings. Together the four informants allowed this study to explore how companies engage and execute sustainability in their footwear product development process.

The findings highlighted the relationship between sustainable goals set in place by corporate structures and the enacted practices of employees in product development roles. 
Analyzing the enacted practices revealed the power and limitations of product developers. Product developers expressed their domains of influence, that is, where they felt they had the most power and opportunity to execute sustainability initiatives. Limitations highlighted how they were hampered from external and internal influences. Understanding product developers' limitations and power sources is helpful for both academics and practitioners as it illustrates how and where disconnect between sustainability goals and outcomes might emanate. For practitioners, this understanding could provide insight into where they can resolve conflict between corporate structures and product developers resulting in higher success of sustainable initiatives. From an academic understanding this could stimulate further research into how the internal and external influences that inhibit sustainable growth. When exploring the areas of power and limitation, it was found that the employee's corporate structures contributed to their limitations and powers sources. Specifically, Chloe was limited more internally than Sierra with corporate pricing structures and lack of accessibility and traceability in Company S's supply chains. These limitations existed because of the companies' business model did not fully align with sustainability. This observation complimented Jacques (2010) in that he found companies investment majorly affects product development teams across the footwear industry. Sierra's companies' business model did align with the company's sustainability values and contributed to her acquiring more domains of influence in executing sustainability.

Though corporate structures contributed majorly to how Sierra and Chloe engaged and executed sustainability, James and Austin reflected how lack of a corporate structure contributed to their sustainability response. While both expressed concerns for the footwear industry's negative environmental impact neither focused executing any sustainability initiatives within 
their roles. This could be due to their positions as freelancers as their employment relies on fulfilling a multitude of outside expectations for product development as well as their lack of engagement with the manufacturing, material sourcing for footwear products. These findings contributed to the understanding of how corporate structures and internal entities influence product developers.

The findings highlighted how Chloe and Sierra were challenged in their pursuit of more sustainable materials, specifically recycled plastic, and rubber. The alternatives available did not meet their company's cost, quality, and durability standards. They both credited these limitations to the newness of sustainability as a focus in the footwear industry and the lack of formality within the industry. The newness of sustainability as a focus in the global supply chain created conflict executing sustainable practices in product development and manufacturing stages of companies and their suppliers. Revealing that no matter the level of sustainable progression within a corporate structure they were still hindered when sourcing within the global supply chain. Moon (2013) explained that the complexity of implementing sustainability into the global market results in the conclusion that a "product cannot be regarded as perfectly sustainable" (p.393). This appeared to be the case in this context as well. Because of the complexities in the global market, Chloe and Sierra were hindered in executing sustainability. This study contributes to understanding how sustainability as a new focus for the fashion industry creates barriers that may continue to frustrate those tasked with enacting sustainability goals in short time frames. Those barriers also reflect the effects of corporate structures treating sustainability as a secondary role within an unsustainable industry. The potential opportunities that come when applying sustainability into the structures of the global supply chain have yet to revealed. 
Though one hopes that as sustainability matures in the industry that barriers will ease on product developers' roles.

Findings suggest that sustainability still needs time to grow in the industry. The next step in understanding the sustainability effect in footwear companies is understanding how sustainability is being engaged and executed within the global supply chain. Through the phenomenological approach this study was able to gain an understanding of product developers' roles and how their corporate structures influenced their ability to enact sustainability initiatives. This research has contributed to a better understanding of the negative environmental impacts of the footwear industry. It is evident from this research that there are many contributing factors as to why footwear products are not sustainable. The diversity of footwear company sizes, business models, and the complexity of the global supply chain suggests there is little guidance in how to navigate sustainability. As a result, companies across the industry are engaging and executing sustainability in an ad hoc way. This study aligned with product developers to provide an understanding of the phenomenon. Creswell and Poth (2018) suggested exploring a lived experience results in an overall understanding of the phenomenon. Through exploration of product developers experiences this study provided an understanding of how sustainability as a phenomenon is affecting footwear companies and product development. 


\section{References}

A Trusted Daily Source for Fashion, Law, Business \& Culture. (2020, May 08). Retrieved December 14, 2020, from https://www.thefashionlaw.com/

Barney, J. (1991). Firm Resources and Sustained Competitive Advantage. Journal of Management, 17(1), 99-120. doi:10.1177/014920639101700108

Baxter, P., \&amp; Jack, S. (2008). Qualitative case study methodology: Study design and implementation for novice researchers. The Qualitative Report. doi:10.46743/2160$3715 / 2008.1573$

Bhardwaj, V., \& Fairhurst, A. (2010). Fast fashion: Response to changes in the fashion industry. The International Review of Retail, Distribution and Consumer Research, 20(1), 165-173. doi:10.1080/09593960903498300

Bocken, N., Short, S., Rana, P., \& Evans, S. (2013). A literature and practice review to develop sustainable business model archetypes. Journal of Cleaner Production, 65, 42-56. doi:10.1016/j.jclepro.2013.11.039

Brewer, M. K. (2019). Slow Fashion in a Fast Fashion World: Promoting Sustainability and Responsibility. Laws, 8(4), 24. doi:10.3390/laws8040024

Chan, H., Wei, X., Guo, S., \& Leung, W. (2020). Corporate social responsibility (CSR) in fashion supply chains: A multi-methodological study. Transportation Research Part E: Logistics and Transportation Review, 142, 102063. doi:10.1016/j.tre.2020.102063

Cheung Acquisition Marketing Manager at Sojern Follow, G. (2010). Brand analysis: The north face. Retrieved April 18, 2021, from https:/www.slideshare.net/gracecheung/brandanalysis-the-north-face

Chrisman, J. J., Hofer, C. W., \& Boulton, W. B. (1988). Toward a System for Classifying Business Strategies. Academy of Management Review, 13(3), 413-428. doi:10.5465/amr.1988.4306963

Creswell, J. W., \& Poth, C. N. (2018). Qualitative inquiry \& research design: Choosing among five approaches. Los Angeles, CA: SAGE Publication.

Curwen, L. G., Park, J., \& Sarkar, A. K. (2013). Challenges and solutions of sustainable apparel product development. Clothing and Textiles Research Journal, 31(1), 32-47. doi: $10.1177 / 0887302 \times 12472724$ 
Darwin Holmes, A. G. (2020). Researcher positionality - a consideration of its influence and place in qualitative research - a new Researcher guide. Shanlax International Journal of Education, 8(4), 1-10. doi:10.34293/education.v8i4.3232

Deniz, D. (2016). Sustainable Thinking and Environmental Awareness through Design Education. Procedia Environmental Sciences, 34, 70-79. doi:10.1016/j.proenv.2016.04.008

Dolan, P., \& Peasgood, T. (2006). Measuring Well-Being for Public Policy. Law and Happiness, 5-32. doi:10.7208/chicago/9780226676029.003.0002

Draper, S. (2015). Creating the big shift: System innovation for sustainability. London: Forum for the Future.

Ertekin, Z. O., \& Atik, D. (2014). Sustainable Markets. Journal of Macromarketing, 35(1), 5369. doi:10.1177/0276146714535932

Evans, S., Fernando, L., \& Yang, M. (2017). Sustainable value creation-from concept towards implementation. Sustainable Manufacturing, 203-220. doi:10.1007/978-3-319-48514-0_13

Fashion transparency INDEX 2020. (2020). Retrieved April 18, 2021, from https://issuu.com/fashionrevolution/docs/fr_fashiontransparencyindex2020?fr=sNmI5NzY xMDk0OA

Filho, J. C., Nunhes, T. V., \&amp; Oliveira, O. J. (2019). Guidelines for cleaner production implementation and management in the plastic footwear industry. Journal of Cleaner Production, 232, 822-838. doi:10.1016/j.jclepro.2019.05.343

Fletcher, K. (2014). Sustainable Fashion and Textiles. doi:10.4324/9781849772778

Garcia-Torres, S., Albareda, L., Rey-Garcia, M., \& Seuring, S. (2019). Traceability for sustainability - literature review and conceptual framework. Supply Chain Management: An International Journal, 24(1), 85-106. doi:10.1108/scm-04-2018-0152

Gongini, B. (2017, October 27). SUSTAINABLE FASHION STARTS WITH ETHICAL \&amp; FAIR TRADE DESIGN: CLOTHING FOR A BETTER FUTURE. Retrieved April 18, 2021, from https://barbaraigongini.com/universe/blog/sustainable-fashion-design/

Jacques, J. J., Agogino, A. M., \& Guimara es, L. B. (2010). Sustainable Product Development Initiatives in the Footwear Industry Based on the Cradle to Cradle Concept. Volume 6: 15th Design for Manufacturing and the Lifecycle Conference; 7th Symposium on International Design and Design Education. doi:10.1115/detc2010-29061

Khan, Shahid. (2014). Qualitative Research Method - Phenomenology. Asian Social Science. 10. 298-310. 10.5539/ass.v10n21p298. 
Kumar, V., Hallqvist, C., \& Ekwall, D. (2017). Developing a Framework for Traceability Implementation in the Textile Supply Chain. Systems, 5(2), 33.

doi:10.3390/systems5020033

Locke, R. (2002). The Promise and Perils of Globalization: The Case of Nike. IPC Working Paper Series. doi:10.7551/mitpress/4412.003.0009

Lueg, R., Pedersen, M. M., \& Clemmensen, S. N. (2013). The Role of Corporate Sustainability in a Low-Cost Business Model - A Case Study in the Scandinavian Fashion Industry. Business Strategy and the Environment, 24(5), 344-359. doi:10.1002/bse.1825

Marconi, M., Marilungo, E., Papetti, A., \& Germani, M. (2017). Traceability as a means to investigate supply chain sustainability: The real case of a leather shoe supply chain. International Journal of Production Research, 55(22), 6638-6652. doi:10.1080/00207543.2017.1332437

Marshall, M. N. (1996). Sampling for qualitative research. Family Practice, 13(6), 522-526. doi:10.1093/fampra/13.6.522

McRobbie, Angela. 1997. A New Kind of Rag Trade? The Politics of British Fashion design. In: Andrew Ross, ed. No Sweat: Fashion, Free Trade and the Rights of Workers: Fashion, Free Trade and the Rights of Garment Workers. New York: Verso, pp. 275-290. ISBN 9781859841723

Moon, K. K., Youn, C., Chang, J. M., \& Yeung, A. W. (2013). Product design scenarios for energy saving: A case study of fashion apparel. International Journal of Production Economics, 146(2), 392-401. doi:10.1016/j.ijpe.2013.02.024

Moorhouse, D., \& Moorhouse, D. (2017). Sustainable Design: Circular Economy in Fashion and Textiles. The Design Journal, 20(Sup1). doi:10.1080/14606925.2017.1352713

Murray, R. (2002). Zero waste. London: Greenpeace Environmental Trust.

Murray, M., \& Chamberlain, K. (1999). Health psychology and qualitative research. Qualitative Health Psychology: Theories and Methods, 3-15. doi:10.4135/9781446217870.n1

Nike. Just Do It. (n.d.). Retrieved December 14, 2020, from https://www.nike.com/

O'rafferty, S., Curtis, H., \& O'connor, F. (2014). Mainstreaming sustainability in design education - a capacity building framework. International Journal of Sustainability in Higher Education, 15(2), 169-187. doi:10.1108/ijshe-05-2012-0044

O'Rourke, D. (2008). Market movements: Nongovernmental organization strategies to influence global production and consumption. Journal of Industrial Ecology, 9(1-2), 115-128. doi:10.1162/1088198054084608 
Panayotou, Theodore. "Globalization and Environment.” CID Working Paper Series 2000.53, Harvard University, Cambridge, MA, July 2000.

Park, H., \& Dickson, M. A. (2008). Engaging in Buyer-Seller Partnership for Fair Labor Management. Clothing and Textiles Research Journal, 26(1), 41-56. doi: $10.1177 / 0887302 \times 07304127$

Park, H., \& Stoel, L. (2005). A model of socially responsible buying/sourcing decision-making processes. International Journal of Retail \& Distribution Management, 33(4), 235-248. doi:10.1108/09590550510593176

Prendeville, S., Hartung, G., Purvis, E., Brass, C., \& Hall, A. (2016). Makespaces: From Redistributed Manufacturing to a Circular Economy. Sustainable Design and Manufacturing 2016 Smart Innovation, Systems and Technologies, 577-588. doi:10.1007/978-3-319-32098-4_49

Protocol 7.0 our newest protocol is available now. (2021). Retrieved April 18, 2021, from https://www.leatherworkinggroup.com/

Radhakrishnan, S. (2014). The Sustainable Apparel Coalition and the Higg Index. Textile Science and Clothing Technology Roadmap to Sustainable Textiles and Clothing, 23-57. doi:10.1007/978-981-287-164-0_2

Ryan, G. (2018). Introduction to positivism, interpretivism and critical theory. Nurse Researcher, 25(4), 14-20. doi:10.7748/nr.2018.e1466

Sameer, Mostafa. (2020). Environmental Impact of Shoe Manufacturing Process. 10.13140/RG.2.2.31678.72002.

SMB, SME, and Large Enterprise: Business Size Classification Matters. Sangoma. (2021, April 1). https://www.sangoma.com/articles/smb-sme-large-enterprise-size-business-matters/.

Shu-Chuan Chu \& Yoojung Kim (2011) Determinants of consumer engagement in electronic word-of-mouth (eWOM) in social networking sites, International Journal of Advertising, 30:1, 47-75, DOI: 10.2501/IJA-30-1-047-075

Slow fashion. (2007, November 17). Retrieved December 13, 2020, from https://theecologist.org/2007/jun/01/slow-fashion

Subic, A., Shabani, B., Hedayati, M., \& Crossin, E. (2012). Capability Framework for Sustainable Manufacturing of Sports Apparel and Footwear. Sustainability, 4(9), $2127-$ 2145. doi:10.3390/su4092127 
Sustainable Value Analysis Tool. Reprinted from "A Value Mapping Tool for Sustainable Business Modelling" by N. Bocken, S. Short, P. Rana, and S. Evans, 2013, Corporate Governance International Journal of Business in Society 13 (5): 482- 497.

Turner, C., Moreno, M., Mondini, L., Salonitis, K., Charnley, F., Tiwari, A., \& Hutabarat, W. (2019). Sustainable Production in a Circular Economy: A Business Model for ReDistributed Manufacturing. Sustainability, 11(16), 4291. doi:10.3390/su11164291

Value Propositions. Reprinted from "A Value Mapping Tool for Sustainable Business Modelling" by N. Bocken, S. Short, P. Rana, and S. Evans, 2013, Corporate Governance International Journal of Business in Society 13 (5): $482-497$.

Vezzoli, C. (2003). A new generation of designers: Perspectives for education and training in the field of sustainable design. Experiences and projects at the Politecnico di Milano University. Journal of Cleaner Production, 11(1), 1-9. doi:10.1016/s0959-6526(02)000574

Wilson, A. (2015). A guide to phenomenological research. Nursing Standard, 29(34), 38-43. doi:10.7748/ns.29.34.38.e8821

Wolfe, A. J. (2008, October 02). Nylon: A revolution in textiles. Retrieved April 18, 2021, from https://www.sciencehistory.org/distillations/nylon-a-revolution-in-textiles

Yang, Miying \& Vladimirova, Doroteya \& Rana, P. \& Evans, Steve. (2014). Sustainable value analysis tool for value creation. Asian Journal of Management Science and Applications. 1. 312-332. 10.1504/AJMSA.2014.070649.

Yin, R. K. (2016). Qualitative Research from Start to Finish. Guilford Press.

Yu, X. (2007). Impacts of Corporate Code of Conduct on Labor Standards: A Case Study of Reebok's Athletic Footwear Supplier Factory in China. Journal of Business Ethics, 81(3), 513-529. doi:10.1007/s10551-007-9521-2 


\section{Appendix A: IRB Approval Application}

\section{WestVirginiaUniversity. \\ OFFICE OF HUMAN RESEARCH PROTECTIONS}

886 Chestnut Ridge Road Morgantown, WV 26506

\section{Acknowledgement of Exemption}

$03 / 31 / 2021$

To: Kathryn Jones

From: WVU Office of Research Integrity \& Compliance

Protocol Type: Exempt

Submission Type: Initial

Funding: N/A

WVU Protocol \#: 2103254267

Protocol Title: A Case Study of How Sustainability Affects Footwear Companies and ProductDevelopment

The West Virginia University Institutional Review Board has reviewed your submission of

Exemptprotocol 2103254267. Additional details regarding the review are below:

- This research study was granted an exemption because the Research involves educational tests, survey procedures, interview procedures or observation of public behavior and (i) information obtained is recorded in such a manner that human subjects cannot be identified, directly or through identifiers linked to the subjects; and (ii) any disclosure of the human subjects responses outside theresearch could not reasonably place the subjects at risk of criminal or civil liability or be damaging to the subjects financial standing, employability, or reputation [45 CFR 46.101(2)]. All exemptions are only good for three years. If this research extends more than three years 
beyond the approved date, then the researcher will have to request another exemption. The following documents have been acknowledged for use in this study and are available in the WVU+kc system:

- This research study was granted an exemption for secondary research for which consent is notrequired: use of identifiable information or identifiable biospecimen that have been or will becollected for some other 'primary' or 'initial' activity [45 CFR 46.101(4)].

The following documents were reviewed and approved for use as part of this submission. Only the documents listed below may be used in the research. Please access and print the files in the Notes \& Attachments section of your approved protocolRecruitment Email.pdf

- Interview Instrument.pdf

\section{WVU IRB acknowledgement of protocol 2103254267 will expire on 03/30/2026.}

1. There is no continuing review option for Exempt studies. If this study is still active after five (5) years and you intend to continue, you will need to resubmit a new protocol for approval no less than three (3)weeks prior to the expiration date in order to ensure compliance.

2. Amendments are not accepted on Exempt studies and are not required as long as there is no increase torisk to participants and changes do not exclude the study from Exempt status.

3. The IRB must be notified if there is an increase in risk to participants or if changes to the study exclude the study from Exempt status. In any of these cases, this protocol must be submitted as a new submissionin WVU+kc.

4. Unanticipated, serious adverse events and/or side effect(s) encountered at WVU or an affiliate site thatare related to the research must be reported to the WVU IRB within five (5) days using the Notify IRBaction in WVU+kc.

5. Any Unanticipated Problem or UPIRTSO or other research related event resulting in new or increasedrisk of harm to study subjects, occuring at WVU or an affiliate site, must be reported to the WVU IRBwithin five (5) days using the Notify IRB action in WVU+kc.

6. All research personnel performing tasks related to the research must complete and remain current for therequired training as applicable to the protocol reference above.

The WVU Office of Human Research Protections will be glad to provide assistance to you throughoutthe research process. Please feel free to contact us by phone, at 304.293 .7073 or by email at IRB@mail.wvu.edu.

Sincerely,

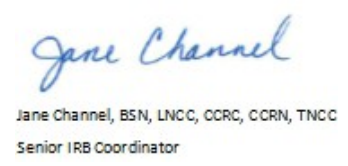




\section{Appendix B: Participant Recruitment Letter}

Dear (Name of Participant):

My name is Mary Hale, and I am a graduate student at West Virginia University in Morgantown, West Virginia. I am conducting a research study as apart of my requirements of my master's degree in Fashion Design. My research aims to discover the affects of sustainability within shoe companies and product development. Along with myself as co-investigator, Kathryn Jones of the Fashion Design and Merchandising department at West Virginia University will serve as the principal investigator.

You are receiving this email as you expressed interest in becoming a participant of the study. I am asking you to volunteer to participate in my study. You will be asked to participate in an interview that will last between 30 to 40 minutes. We will work on scheduling a day and time for the interview that will work around your daily hours at The North Face. This interview will consist of a series of open- ended questions regarding your knowledge of sustainability in the footwear industry. You do not have to answer every question. There will be other questions regarding your job descriptions and tasks within the company. This will take place over zoom. This study's WVU IRB acknowledgement is on file.

Again, your participation in this study is voluntary and you do not have to be a part of this study. If you are interested in volunteering to participate or have any questions about the study, please e-mail me at mshale@mix.wvu.edu or call at 304-914-7385.

Thank you for your consideration.

Sincerely,

Mary Hale 


\section{Appendix C: Interview Prompt}

\section{Demographic}

1. How long have you been with the company?

2. Please describe the current positions you hold within this company.

3. Please describe previous positions you held within this company if any.

\section{Sustainability}

4. What would you say your companies' sustainable initiatives focus on the most out of the following: environmental, social, or economic impacts?

5. Which initiatives are directly addressing one or more of these areas?

6. How has the growth of environmental consciousness amongst consumers affected the companies like business model? How might continued growth in consumer consciousness affect in the future?

7. What are some sustainable initiatives implemented in footwear production?

8. Have you seen any negative outcomes from sustainable efforts in the footwear industry?

\section{SVAT}

9. Who are the stakeholders in footwear?

10. What are some noticeable economic benefits your company has experienced from sustainable initiatives, if any?

11. What are they socially?

12. How about environmentally?

13. Where do you see sustainability initiatives having the biggest impact in the footwear product life cycle?

14. What design implications do you consider when designing for footwear products end of life? Disposal, disassembly?

15. How important do you feel your role is in initiating sustainability?

16. How are you restricted in implementing sustainability when designing footwear?

17. Where do you feel the restrictions come from?

18. How do you identify areas to implement sustainability in footwear development?

\section{Production}

19. How do you manage sustainable initiative in the company's manufacturing process?

20. How do you track the products environmental impact during production?

21. How do your production protocols help you understand where further change could be implemented to create sustainable value?

22. How does the company's partnerships with organizations help reach ethical and sustainable goals?

23. How would you describe the designer's relationship with contractors?

24. How do your suppliers meet your sustainable expectations and regulations?

25 . Is there anything else that you would like to add about sustainable initiatives from your perspective? 


\section{Appendix D: Protection of Participants}

This section will cover the ethical issues and protocols used during research to protect participants. Because this research used human participants, the concerns lie within the humane treatment and ensuring participants' rights. The researcher received the required training to protect human subjects and approve an IRB (Institutional Review Board) application. The protocol number is: 2103254267 . Retrieval of these documents addresses the ethical issues found in the use of human participants. The protocols used in this research protect all participants. Note that names of all participants have been changed to a pseudonym to protect their identity.

The researcher chose to reach out to Chloe of Company S regarding an interview. An initial message was sent through LinkedIn, and a follow-up email was sent to Chloe requesting her consent and assistance in seeking out other participants. A document detailing participants' expectation and a short overview of the study was sent through email. Sierra was reached out to through mutual connections and sent an email requesting participation in the interview. The email was the same as the email sent to Sierra and included a short overview of the study. Freelancers were contacted through social media and sent the same document by email. They responded to the interview through email due to language and time barriers.

Chloe and Sierra were communicated with through email and sent a recruitment letter

(see Appendix B). The recruitment letter included protocols that protected the participants, such as the right not to answer every interview question. Once participants agreed to participate an interview was scheduled at their convenience. At the interview, the researcher again discussed the recruitment letter protocols ensuring that participants fully understood the activities before starting the interview. 
The interview data and email responses reviewed and collected were handled following the written protocols to ensure safe handling and storage of information. The protocol ensures that the interview documents were safely stored in the researcher's password-protected laptop. Documents and information stored will be deleted after the completion of the research. Participants and companies were given pseudonyms to protect identities.

Before each interview, participants were informed that the session would be recorded and that they were free to stop the interview at any time. Participants were also reminded of their rights to not answer any questions and withdraw at any time. The interviews were no longer than 60 minutes to prevent interfering with the daily tasks of participants. 